\title{
Oral Delivery of Insulin: Novel Approaches
}

\author{
Amani M. Elsayed
}

Additional information is available at the end of the chapter

http://dx.doi.org/10.5772/52265

\section{Introduction}

\subsection{Insulin: physicochemical properties and function}

Insulin is a hormone that is synthesized in the $\beta$-cells of the pancreas as a proinsulin precursor and is converted to insulin by enzymatic cleavage. The resulting insulin molecule is composed of 51 amino acids arranged into two polypeptide chains - the A and B chains which are connected by two interchain disulphide bridges. In the A chain, there is an additional intrachain disulphide linkage [1]. The primary structure of human insulin is shown in Figure 1 a. In the secondary structure, chain A consists of two antiparallel $\alpha$ helices ( $\mathrm{A}_{2}$ to $\mathrm{A}_{8}$ and $\mathrm{A}_{13}$ to $\mathrm{A}_{20}$ ), while chain $\mathrm{B}$ forms a single $\alpha$-helix " $\mathrm{B}_{9}$ to $\mathrm{B}_{19}$ " followed by a turn and a $\beta$ strand " $\mathrm{B}_{21}$ and $\mathrm{B}_{30}$ " [2]. The folding of insulin into a tertiary structure is essential for its biological activity (Figure 1b). Insulin has an isoelectric point (pI) of 5.3 and a charge of -2 to -6 in the $\mathrm{pH}$ range 7-11. Another intrinsic property of insulin is its ability to readily associate into dimmers, hexamers and higher-order aggregates. At the low concentrations found in the blood stream $\left(<10^{-3} \mu \mathrm{M}\right)$, insulin exists as a monomer, which is its biologically active form. Following biosynthesis, insulin is stored as crystalline zincbound hexamers in vesicles within the pancreatic $\beta$-cells from which secretion occurs in response to elevated blood glucose levels [3]. The biological actions of insulin are initiated when insulin binds to its cell surface receptor. Insulin is an anabolic hormone and when binding to its receptor begins, many protein activation cascades occur. These include: the translocation of the glucose transporter to the plasma membrane and the influx of glucose, glycogen synthesis, glycolysis and fatty acid synthesis. Insulin has been observed as promoting the transport of some amino acids and potassium ions. Insulin also inhibits the liberation of free fatty acids and glycerol from the adipose tissue [3].

Insulin is used for the treatment of diabetes, a disease which results from a defect in the secretion or action of insulin. 

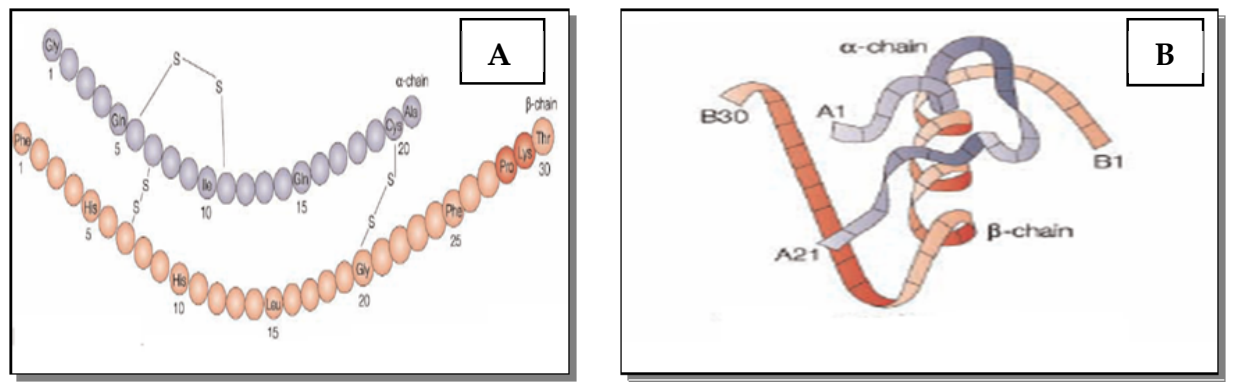

Figure 1. Insulin: a) Primary Structure b) Tertiary Structure

\subsection{Oral delivery of insulin: Why?}

Insulin is introduced by the parenteral route and two or three injections are needed for the better control of diabetes and in order to reduce the long term complications of hyperglycaemia (retinopathy, neuropathy and nephropathy). Patient non-compliance is common with the parenteral route. In addition, repeated injections will cause lipoatrophy or lipohypertrophy. Moreover, insulin injected into the subcutaneous tissues goes directly into general circulation and leads to peripheral hyperinsulinemia, which is associated with peripheral hypertension, the development of atherosclerosis, cancer, hypoglycaemia and other adverse metabolic effects [4]. Thus, the conventional subcutaneous injection of insulin is unphysiological because it deprives patients of the benefits of portal insulin since the liver is the major metabolic modulator of the glucose metabolism.

Oral insulin is a dream of patients and a challenge for scientists. For patients, not only are the pain and stress of injections relieved but it may also protect beta cells, avoid the weight gain associated with insulin injections and correct the blunting of the first-phase release of insulin [5]. All these effects are due to the fact that oral route provide insulin directly to the liver through portal circulation, resembling that which occurs in the non-diabetic individual [6]. The achievement of an adequate level of insulin in portal circulation has been associated with more a rapid and significant lowering of plasma glucose and haemoglobin A1c levels, the normalization of the plasma levels of three carbon precursors - such as lactate, pyruvate and alanine - and the hormones cortisol, growth hormone and glucagon [7].

Another advantage of oral insulin is that the gastrointestinal tract is immune tolerant compared to other routes of drug administration since immunogenicity has become a major issue for most biotechnology products. Immunogenicity decreases in the following order: (inhalation $>$ subcutaneous $>$ intramuscular $>$ intravenous $>$ oral).

For scientists, greater effort is needed to develop a nontoxic, stable, bioactive oral insulin delivery system. To develop such systems, many barriers must be explored.

\subsection{Obstacles to oral delivery}

The major barrier is that of absorption through the gastrointestinal membrane. Generally, the absorption of molecules can occur through the paracellular or the transcellular route. 
The former is the preferred route for small hydrophilic molecules with a molecular weight below $500 \mathrm{Da}$ [8]. Of course, molecules with a high molecular weight - such as insulin (about $6 \mathrm{KDa}$ ) - would not penetrate through this route. This large molecular size, its charge and its hydrophilicity all preclude insulin absorption by transcellular diffusion.

Another obstacle is those enzymes that are located throughout the GIT. In the stomach there is a family of aspartic proteases called pepsins. In the small intestine, pancreatic proteases consisting of the serine endopeptidase (trypsin, $\alpha$-chymotrypsin, elastase and exopeptidases, carboxypeptidases A and B) are responsible for the degradation of proteins [9]. Other enzymes are located at the brush-border membrane (various peptidases) or within the enterocytes of the intestinal tract. It was demonstrated by Aoki et al. [10] that the enzymatic degradation activity for insulin in the mucous/glycocalyx layers tends to increase towards the upper small intestine in the following order: duodenum $>$ jejunum $>$ ileum.

Another challenge for the formulator is the stability of insulin. Insulin has a delicate structure, and both formulation and processing parameters could influence its stability [11]. The most common degradation reactions are deamidation and polymerization. Extensive deamidation at the residue $\mathrm{Asn}^{\mathrm{A} 21}$ of insulin occurs in acid solutions, while in neutral formulations deamidation takes place at $\mathrm{Asn}^{\mathrm{B} 3}$ at a substantially reduced rate [12]. High temperatures accelerate the formation of covalent insulin dimer and covalent insulin polymer [13].

The formulator could handle the enzyme and stability barriers. A well-formulated nanocarrier would protect insulin from enzymes. Also, and with the proper choice of excipients and a properly designed method of production, the stability of insulin could be preserved. Many investigated systems have overcome these two barriers. However, no system exhibits a reproducible and pronounced absorption.

\subsection{Approaches explored to overcome the obstacles}

To improve the bioavailability of insulin, different approaches have been explored, including chemical modification [14], co-administration with absorption enhancers and/or enzyme inhibitors [15] and incorporation into carriers, such as liposomes ]16], mixed micelles, lipid-based systems, microspheres and nanoparticles [17-20].

\subsubsection{Nanocarriers}

These are carriers with a particle size of less than $1000 \mathrm{~nm}$. Nanocarriers have received more attention recently due to their submicron size and their large specific surface area, both of which favour their absorption compared to larger carriers.

\subsubsection{Types}

Nanocarriers are categorized into: polymeric nanoparticles, nanovesicles and solid lipid nanoparticles (Figure 2). There are two types of polymeric nanoparticles: the matrix particles termed 'nanospheres' and the reservoir-type named 'nanocapsules'. Vesicles have a hydrophilic core and hydrophobic bilayers. Conventionally, liposomal vesicles were 
developed by the self-assembly of phospholipid molecules in an aqueous environment. Recently, polymeric vesicles were prepared from amphiphilic polymers which form aggregates in aqueous solutions [21]. Solid lipid nanoparticles (SLN) are submicron colloidal carriers prepared from solid lipids (lipids being solid at room and body temperatures), such as triacylglycerols, complex acylglycerol mixtures or waxes, and dispersed either in water or in an aqueous surfactant solution [22]. The important features of different nanocarriers are illustrated in Table 1.

\subsubsection{Applications}

\subsection{Liposomes}

Insulin-loaded liposomes containing different kinds of bile salts (glycocholate, sodium taurocholate or sodium deoxycholate) were prepared by a reversed-phase evaporation method and their hypoglycaemic activity was assessed after oral administration to male Wistar rats. Liposomes containing sodium glycocholate elicited higher bioavailability - of approximately $8.5 \%$ and $11.0 \%$ - in non-diabetic and diabetic rats, respectively [23]. A hepatic-directed vesicle insulin system (HDV-I) was developed by Diasome Pharmaceuticals, Inc. The vesicles contain a specific proprietary hepatocyte-targeting molecule - biotinphosphatidylethanolamine - in their phospholipid bilayer. Clinical trials in adult patients with type 1 diabetes mellitus demonstrated that the postprandial glycaemic control produced by 0.1 and $0.2 \mathrm{U} / \mathrm{kg}$ oral HDV-I was similar to that produced by $0.07 \mathrm{U} / \mathrm{kg}$ SC Humulin R [7].

\subsection{Polymeric nanovesicles}

Poly(lactic acid)-b-Pluronic-b-poly(lactic acid) block copolymers were synthesized [21]. This amphiphilic block copolymer aggregates in an aqueous solution to form vesicular nanoparticles. The oral administration of insulin-loaded vesicles to diabetic mice resulted in the reduction of blood glucose levels - $25 \%$ of the initial glucose level - which was maintained at this level for an additional $18.5 \mathrm{~h} \mathrm{[21].}$

\subsection{Solid Lipid Nanoparticles (SLN)}

Sarmento et al. [24] prepared insulin-loaded cetyl palmitate solid lipid nanoparticles and demonstrated their potential to deliver insulin orally. The drug loading capacity in solid lipid nanoparticles was improved by enhancing insulin liposolubility. Insulin was solubilized into mixed reverse micelles of sodium cholate and soybean phosphatidylcholine and transformed into SLN using a novel reverse micelle-double emulsion technique. Stearic acid and palmatic acid were used as a biocompatible lipid matrix [25]. The surface of the nanoparticles was modified by chitosan to enhance their penetration through GIT. In addition, chitosan was able to provide stealth properties to SLN, resulting in the absence of phagocytosis. Pharmacological availability values of $5.1-8.3 \%$ for SLN and $17.7 \%$ for chitosan-coated SLN were reported [26]. Lectins are proteins that bind sugar reversibly and are involved in many cell recognition and adhesion processes. They have been extensively adopted to target both absorptive enterocytes and $\mathrm{M}$ cells [27]. Wheat germ agglutinin binds (WGA) specifically to cell membranes and is taken up into cells by receptor-mediated endocytosis [28]. Zhang et al. [29] utilized the advantages of WGA and formulated SLN 


\begin{tabular}{|l|l|l|}
\hline Nanocarrier & Advantages & Shortcomings \\
\hline nolymeric & $\begin{array}{l}\text { Various polymeric materials } \\
\text { (hydrophobic and hydrophilic) can be } \\
\text { used to modulate the physicochemical } \\
\text { properties of NPs (e.g., surface charge } \\
\text { and mucoadhesivity), encapsulation } \\
\text { efficiency, drug release profile and } \\
\text { biological behaviour }\end{array}$ & $\begin{array}{l}\text { Denaturation can occur during } \\
\text { encapsulation in synthetic } \\
\text { polymers, due largely to } \\
\text { exposure to organic solvents, } \\
\text { elevated temperatures and } \\
\text { aqueous organic interfaces. } \\
\text { Cytotoxicity of polymers after } \\
\text { internalization into cells }\end{array}$ \\
\hline Liposomes & $\begin{array}{l}\text { Good permeation property since their } \\
\text { bilayer structure is similar to that of the } \\
\text { cell membrane }\end{array}$ & $\begin{array}{l}\text { Poor entrapment efficiency } \\
\text { Stability in biological fluids } \\
\text { was relatively weak }\end{array}$ \\
\hline $\begin{array}{l}\text { Polymeric } \\
\text { nanovesicles }\end{array}$ & $\begin{array}{l}\text { More stable than liposomes } \\
\text { The properties of polymeric vesicles, } \\
\text { such as the size and the thickness of the } \\
\text { bilayer, can be varied by changing the } \\
\text { molecular weight and block composition } \\
\text { of the polymer }\end{array}$ & $\begin{array}{l}\text { Cytotoxicity of polymers after } \\
\text { internalization into cells }\end{array}$ \\
$\begin{array}{l}\text { Tolerability, Biodegradability } \\
\text { Composed of physiological lipids, which } \\
\text { minimizes the risk of acute and chronic } \\
\text { toxicity. } \\
\text { Possibility of production on a large } \\
\text { industrial scale }\end{array}$ & $\begin{array}{l}\begin{array}{l}\text { Poor encapsulation efficiency } \\
\text { of water-soluble proteins and } \\
\text { peptides into the lipid core } \\
\text { The high temperatures } \\
\text { required to melt the lipid may } \\
\text { affect the stability of insulin } \\
\text { Slow degradation }\end{array} \\
\text { nanoparticles }\end{array}$ \\
\hline
\end{tabular}

Table 1. Nanocarriers: general advantages and shortcomings

modified with WGA to enhance the oral delivery of insulin. Insulin-loaded SLNs or WGAmodified SLNs were administered orally to rats and elicited relative pharmacological bioavailability values of $4.46 \%$ and $6.08 \%$ and relative bioavailability values of $4.99 \%$ and $7.11 \%$, respectively, in comparison with the subcutaneous injection of insulin.

Polymeric nanoparticles developed from biocompatible and biodegradable polymers are good candidates for insulin delivery

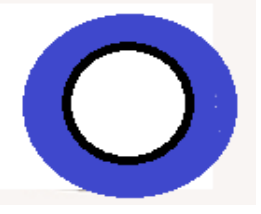

Nanocapsules

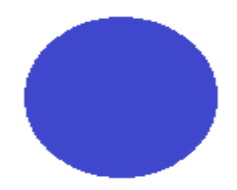

Nanospheres

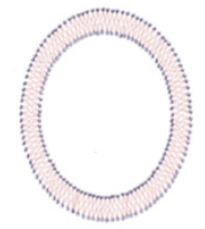

Liposomes

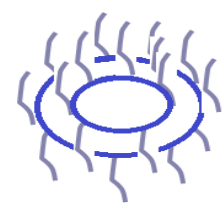

Polymeric nanovesicles

Figure 2. Types of nanocarriers 


\subsubsection{Polymers used for the fabrication of polymeric nanoparticles}

Both synthetic and natural polymers were investigated for the production of nanosystems. These polymers may be used alone or in combination to develop nanoparticles. Several fabrication techniques have been developed and can generally be subdivided into two categories, according to whether a preformed polymer is used or else whether nanoparticles are formed during the polymerization reaction. Methods from the first category include: emulsification/solvent evaporation, solvent displacement and interfacial deposition, emulsification/solvent diffusion, salting out with synthetic polymers, ionotropic gelation, coacervation and polyelectrolyte complexation. Meanwhile, the methods of the second category are: emulsion polymerization, interfacial polymerization and interfacial polycondensation. These methods were thoroughly discussed by Reis et al. [30].

\subsection{Synthetic polymers}

Usually, these are well-defined structures that can be modified to yield reasonable degradability and functionality. Synthetic biodegradable polymers such as poly $\varepsilon$ caprolactone (PCL) poly (lactic-co-glycolic acid) (PLGA) and polylactides (PLA) are widely used in drug delivery due to their good biocompatibility, biodegradability and novel drug release behaviour. The chemical structures of synthetic polymers were depicted in Table 2 and an example of insulin nanoparticles fabricated from these polymers is illustrated in Table 3.

\subsection{PLGA}

Poly (lactic-co-glycolic acid) (PLGA) is an aliphatic polyester synthetic biodegradable biopolymer which is successfully used for the development of nanomedicines. It was also investigated for the delivery of insulin. In the work of Yang et al. [31], insulin was encapsulated in PLGA nanoparticles. The administration of insulin-loaded PLGA nanoparticles for diabetes mellitus induced a rapid decrease in blood glucose levels for up to $24 \mathrm{~h}$ and increased insulin levels. The loading capacity was $78.35 \%$. To facilitate loading efficiency, the lipophilicity of the insulin was increased by complexation with sodium lauryl sulphate or sodium oleate. Insulin encapsulation efficiency reached up to $90 \%$. [32, 33]. Mucoadhesive PLGA nanoparticles were prepared to enhance the oral bioavailability of the negatively charged PLGA nanoparticles. The PLGA nanoparticles were coated with chitosan or Eudragit ${ }^{\circledR}$ RS (RS). The pharmacological availability of two kinds of nanoparticles PLGA nanoparticles and chitosan-coated PLGA nanoparticles - relative to SC injection was calculated and found to be $7.6 \%$ and $10.5 \%$, respectively, at an insulin dose of $15 \mathrm{IU} / \mathrm{kg}$ [34]. Meanwhile, the pharmacological availability of the $50 \mathrm{IU} / \mathrm{kg}$ Eudragit@ RS (RS) coated PLGA nanoparticle was 9.2\% [35]. The main shortcomings of PLGA are that the degradation products arising from degradation of PLGA (lactic and glycolic acid) result in the generation of acidic species which can provoke problems for long-term stability when encapsulating bioactive molecules. Antacid-insulin co-encapsulated PLGA were investigated with a view to increasing the microclimate $\mathrm{pH}$ and preventing structural losses and aggregation [36]. The antacids assessed were magnesium hydroxide and zinc carbonate. However, short-term stability was not reported. 


\subsection{PLA}

Polylactides (PLAs) have similar properties to PLGAs but they are more hydrophobic than PLGAs and they degrade more slowly due to their crystallinity [37]. Cui et al. [38] reported enhanced insulin entrapment efficiency (up to 90\%) in PLA and PLGA nanoparticles, where insulin was complexed with phosphatidylcholine (SPC) to improve its liposolubility. An oral bioavailability of $7.7 \%$ relative to subcutaneous injection was obtained.

\subsection{PCL}

Another interesting biodegradable polyester polymer is poly- $\varepsilon$ caprolactone (PCL). Compared with PLGA and PLA, PCL is semi-crystalline, has superior viscoelastic properties and possesses easy formability. PCL has the advantage of generating a less acidic environment during degradation as compared with PLGA-based polymers [37]. Nevertheless, the hydrophobic nature of PCL affects the encapsulation of hydrophilic substances, such as peptides, enzymes and other proteins. Damgé et al. [39] prepared nanoparticles from a blend of a biodegradable polyester poly ( $\varepsilon$-caprolactone) and a polycationic non-biodegradable acrylic polymer (Eudragit ${ }^{\circ} \mathrm{RS}$ ). These nanoparticles were investigated as a carrier for the oral administration of insulin and demonstrated prolonged hypoglycaemic effect of insulin in both diabetic and normal rats. The same author loaded nanoparticles with regular insulin ((Actrapid, Novo Nordisk) or insulin-Aspart ((Novorapid). Regular insulin-loaded nanoparticles reduced glycaemia in a dose dependent manner with a maximal effect observed with $100 \mathrm{IU} / \mathrm{kg}$. In contrast, insulin analogue did not elicit a dose-dependent hypoglycaemic effect. The maximal effect was observed with $50 \mathrm{IU} / \mathrm{kg}$ insulin while lower $(25 \mathrm{IU} / \mathrm{kg}$ ) and higher doses (100 IU/kg) did not show any significant reduction in glycaemia. The authors attributed these discrepancies to the saturation of the receptors when the dose of aspart-insulin increases to $100 \mathrm{IU} / \mathrm{kg}$ [40].

\subsection{PACA}

Poly (alkyl cyanoacrylate) is a biocompatible and biodegradable polymer. It is degraded by esterases in biological fluids and produces certain toxic products that will stimulate or damage the central nervous system. Thus, this polymer is not authorized for application in humans [41]. However, PACA polymers are used to encapsulate insulin using emulsion or interfacial polymerization. Damge et al. [42] prepared an insulin-loaded poly (alkyl cyanoacrylate) nanocapsule. The oral administration of nanocapsules dispersed in Miglyol 812 to diabetic rats resulted in a 50\% reduction of initial glucose levels from the second hour for up to 10-13 days. This effect was shorter (2 days) or absent when the nanocapsules were dispersed in water, whether with surface active agents or not. Insulin-loaded poly (ethyl cyanoacrylate) nanoparticles were prepared from microemulsions with a different microstructure and were administered orally to diabetic rats. A consistent and significant hypoglycaemic effect over controls was found for up to $36 \mathrm{~h}$ depending upon the type of monomer (ethylcyanoacrylate or butyl cyanoacrylate). However, no significant serum insulin levels were detectable [43]. 


\subsection{Poly (Acrylic acid)}

These are non-degradable polymers with mucoadhesive properties based on acrylic or methacrylic acid. Anionic polymers, such as methyl acrylic acid (Eudragit L-100) and methyl methacrylate (S-100), have been used to formulate $\mathrm{pH}$ sensitive nanocarriers. Polymethacrylic acid-chitosan-polyethylene glycol nanoparticles were developed by Pawar et al. for the oral delivery of insulin. These nanoparticles displayed excellent binding efficiency on mucin from porcine stomach and elicited $\mathrm{pH}$ dependent release profiles in vitro [44]. The nanoparticles were formed by a complex coacervation method using EudragitL100-55 and chitosan of various molecular weights. Insulin release from these nanoparticles was pH-dependent [45]. The distribution, transition and bioadhesion of insulin-loaded pH-sensitive nanoparticles prepared from EudragitL100-55 and chitosan were investigated. The addition of the hydroxypropylmethylcellulose reduced the stomachand intestine-emptying rates and enhanced the adhesion of the nanoparticles to the intestinal mucosa [46].

\subsection{Natural polymers}

The naturally-occurring polymers of particular interest in the oral delivery of insulin are either polysaccharides or else proteins. Polysaccharides include chitosan, hyaluronan, dextran, cellulose, pullulan, chondroitin sulphate and alginate. Meanwhile, the protencious polymers are casein and gelatin. They are nontoxic, biocompatible, biodegradable and hydrophilic. The structure of these natural polymers is illustrated in Table 4. Examples of the natural polymers used to prepare insulin-loaded nanoparticles and the methods used for their fabrication are shown in Table 5.

\subsection{Dextran}

Dextran sulphate is an exocellular bacterial polysaccharide consisting of linear 1,6-linked Dglucopyranose units and branches beginning from $\alpha$-1,3-linkages with approximately 2.3 sulphate groups per glucosyl residue. It is a nontoxic, highly water-soluble, biodegradable and biocompatible branched negatively charged polyion. A nanoparticle insulin delivery system was prepared by the polyelectrolyte complexation of oppositely charged natural polymers - dextran sulphate and chitosan in an aqueous solution. These $\mathrm{pH}$ sensitive nanoparticles released insulin in the intestinal medium [47]. The natural uptake processes of the intestine were utilized for the oral delivery of peptides and proteins. Vitamin B12 is an example of such carriers and was investigated for delivering different peptides [48]. Due to the susceptibility of vitamin B12/peptide conjugate to gastrointestinal degradation, dextran nanoparticles were coated with vitamin B12 and used as a carrier for the oral delivery of insulin [49]. These nanoparticles were found to be targeted at the systemic circulation through vitamin B12-intrinsic factor receptor ligand-mediated endocytosis via ileocytes of the intestine [49]. The \% pharmacological availability of nanoparticle conjugates containing 2, 3 and $4 \% \mathrm{w} / \mathrm{w}$ insulin was 1.1, 1.9 and 2.6 times higher, respectively, compared with nanoparticles without VB12. 


\begin{tabular}{|c|c|}
\hline Polymer & Chemical Structure \\
\hline PLGA & $x=$ number of units of lactic acid \\
& $y=$ number of units of glycolic acid \\
\hline PLA & Polycapolactone \\
\hline $\begin{array}{c}\text { Ethyl } \\
\text { monoacrylate } \\
\text { Poly (acrylic acid) }\end{array}$ & \\
\hline
\end{tabular}

Table 2. Chemical Structure of Synthetic Polymers

\subsection{Alginate}

Alginate is a naturally occurring polysaccharide obtained from marine brown algae. It is a linear copolymer composed of 1,4-linked- $\beta$-D-mannuronic acid and $\alpha$-L-guluronic acid residues that gel in the presence of divalent cations. It is a nontoxic and biodegradable polyanion that forms polyelectrolyte complexes with polycations, such as chitosan. Insulinloaded nanoparticles were prepared by the ionotropic pre-gelation of alginate with calcium chloride followed by complexation between alginate and chitosan [50]. The pharmacological effect of insulin-loaded nanoparticles was evaluated in diabetic rats. The pharmacological availability was $6.8 \%$ and $3.4 \%$ for the 50 and $100 \mathrm{IU} / \mathrm{kg}$ doses, respectively [51]. Alginate/chitosan nanoparticles form complexes with cationic $\beta$-cyclodextrin polymers. The nanoparticles protect insulin against degradation in simulated gastric fluid [52]. Reis et al. [53] evaluated nanoparticle systems composed of alginate/chitosan cores coated with chitosan-polyethylene glycol-albumin. Albumin was added to prevent protease attacks on the insulin and chitosan for its mucoadhesive properties, while PEG served as a nanosphere stabilizer to improve the half-live of the insulin and increase the residence time along the intestine. Chitosan-PEG-albumin coated nanospheres demonstrated a more than $70 \%$ blood glucose reduction, increased insulinemia by a factor of seven and significantly improved the 
response to the glucose oral tolerance test following oral administration to diabetic rats. In contrast, nanospheres lacking albumin and PEG in the coating material were ineffective. Multilayer nanoparticles consisting of calcium cross-linked alginate, dextran sulphate, poloxamer 188, chitosan and an outermost coating of albumin were developed. A 3-factor 3level Box-Behnken statistical design was used to optimize the nanoparticle formulation. Solutions of $0.20 \%$ calcium chloride, $0.04 \%$ chitosan and $0.47 \%$ albumin constituted the optimum formulation of nanoparticles for orally-dosed insulin [54]. The relative pharmacological availability and bioavailability were calculated after oral administration of $50 \mathrm{IU} / \mathrm{kg}$ of insulin-loaded multilayered nanoparticles to diabetic rats and were found to be $11 \%$ and $13 \%$, respectively [55].

\begin{tabular}{|c|c|c|c|c|}
\hline Polymer & Method of preparation & $\begin{array}{c}\text { Particle } \\
\text { size } \\
(\mathbf{n m})\end{array}$ & $\begin{array}{c}\text { Pharmacological } \\
\text { availability (PA)/ or } \\
\text { relative bioavailability } \\
\text { (RBA) }\end{array}$ & Ref. \\
\hline PGLA & $\begin{array}{c}\text { Double-emulsion/solvent } \\
\text { evaporation technique }\end{array}$ & 208 & Not calculated & 31 \\
\hline $\begin{array}{c}\text { PLGA and } \\
\text { chitosan }\end{array}$ & $\begin{array}{c}\text { Water-in oil-in-water } \\
\text { solvent evaporation } \\
\text { technique }\end{array}$ & 150 & PA: 10.5\% & 34 \\
\hline $\begin{array}{c}\text { PLGA, Eudragit }{ }^{\circledR} \\
\text { RS (RS) and } \\
\text { Hydroxypropyl } \\
\text { methylcellulose } \\
\text { phthalate }\end{array}$ & $\begin{array}{c}\text { Multiple emulsions } \\
\text { solvent evaporation } \\
\text { technique. }\end{array}$ & 285 & PA: $9.2 \%$ & 35 \\
\hline $\begin{array}{c}\text { PCL and } \\
\text { Eudragit }{ }^{\circ} \text { RS }\end{array}$ & Double emulsion method & 331 & RBA: $13 \%$ & 39 \\
\hline
\end{tabular}

Table 3. Synthetic polymers used for the preparation of nanoparticles and the methods used for their fabrication

\begin{tabular}{|l|c|}
\hline Polymer & Chemical Structure \\
\hline Dextran & \\
\hline Alginate & \\
\hline Chitosan & \\
\hline
\end{tabular}

Table 4. Chemical Structure of Natural Polymers 
As illustrated in Table 5, the most widely explored polymer is chitosan. This is because of its favourable biological properties, safety, low cost and easy modification. Compared to synthetic polymers, the degradation products of chitosan are amino sugars, which are easily metabolized by the body. Therefore, there is no concern of an acidic microclimate being generated by chitosan particles [56].

\begin{tabular}{|c|c|c|c|c|}
\hline Polymer & Method of preparation & $\begin{array}{l}\text { Particle } \\
\text { size } \\
\text { (nm) }\end{array}$ & $\begin{array}{c}\text { Pharmacological } \\
\text { Availability (PA)/ or } \\
\text { Relative } \\
\text { bioavailability } \\
\text { (RBA) }\end{array}$ & Ref. \\
\hline $\begin{array}{l}\text { Chitosan and Poly } \\
(\gamma \text {-glutamic acid })\end{array}$ & $\begin{array}{l}\text { Ionic-gelation method: the nanoparticles } \\
\text { were freeze-dried and placed in enteric- } \\
\text { coated capsules }\end{array}$ & 232.9 & $\begin{array}{l}\text { RBA: approximately } \\
20 \% \text {. }\end{array}$ & 70 \\
\hline $\begin{array}{l}\text { Chitosan and Poly } \\
\text { ( } \gamma \text {-glutamic acid) }\end{array}$ & $\begin{array}{l}\text { A penetration enhancer (DTPA) was } \\
\text { covalently conjugated on poly (g- } \\
\text { glutamicacid) followed by ionic-gelation } \\
\text { with chitosan }\end{array}$ & 246.6 & $\begin{array}{l}\text { RBA: approximately } \\
20 \%\end{array}$ & 71 \\
\hline $\begin{array}{l}\text { Chitosan, } \\
\text { Alginate, Dextran, } \\
\text { Poloxamer, and } \\
\text { BSA }\end{array}$ & $\begin{array}{l}\text { Ionotropic pre-gelation followed by } \\
\text { polyelectrolyte complexation }\end{array}$ & 396 & RBA: $13.2 \pm 2.9$ & 52 \\
\hline Dextran & $\begin{array}{l}\text { Cross-linking of emulsion to prepare } \\
\text { dextran nanoparticles. The surface was } \\
\text { modified with succinic anhydride and } \\
\text { conjugated with amino VB12 derivatives } \\
\text { of the carbamate linkage. }\end{array}$ & $160-250$ & PA: 26.5 & 49 \\
\hline
\end{tabular}

Table 5. Natural polymers used for the preparation of nanoparticles and the methods used for their fabrication

\section{What is Chitosan?}

Chitosan is a linear copolymer consisting of $ß$ (1-4)-linked 2-amino-2-deoxy-D-glucose (Dglucosamine) and 2-acetamido-2-deoxy-D-glucose ( $\mathrm{N}$-acetyl-D-glucosamine) units (Table 4). It is obtained by the alkaline $\mathrm{N}$-deacetylation of chitin, which is the primary structural component of the outer skeletons of crustaceans. Chitosan is a weak poly base due to the large quantities of amino groups on its chain [57]. Both high molecular weight (HMWC) and low molecular weight chitosans (LMWC) are available. The latter were obtained by the depolymerization of HMWC. This can be carried out by enzymatic [58,59], physical [60, 61] or chemical methods [62, 63]. Another important property of chitosan is the degree of deacetylation (DDA), defined in terms of the percentage of primary amino groups in the 
polymer backbone. The properties of chitosan and its biological role are dependent on the DDA and M.wt [64]. Chitosan dissolves easily at low $\mathrm{pH}$ due to the protonation of the amino groups, while it is insoluble at higher $\mathrm{pH}$ ranges since the amino groups become deprotonated, as the $\mathrm{pH}$ approach the $\mathrm{pKa}$ of chitosan (6-6.5). The solubility of chitosan depends upon the molecular weight and DDA.

Chitosan nanoparticles have been prepared using ionotropic gelation with tripolyphosphate or even simply polyelectrolyte complexation between insulin and chitosan. The interaction of chitosan and polyanions leads to the spontaneous formation of nanoparticles in an aqueous environment without the need for heating or the use of organic solvents [65]. In addition, to ease of preparation under mild conditions, a high level of drug entrapment can be achieved so that the protein secondary structure and biological activity is preserved [66]. Insulin-loaded chitosan nanoparticles were prepared by the ionotropic gelation of chitosan with tripolyphosphate anions [67]. These nanoparticles were effective at lowering the serum glucose level of streptozotocin-induced diabetic rats when administered orally at insulin doses of $50 \mathrm{U} / \mathrm{kg}$ and/or $100 \mathrm{U} / \mathrm{kg}$. However, they dissociate easily in acidic gastric conditions. To protect insulin from harsh GIT conditions, chitosan nanoparticles were formulated with an enteric coating polymer - hydroxypropyl methylcellulose phthalate (HPMCP) - and evaluated for the oral delivery of insulin. HPMCP-chitosan nanoparticles showed a 2.8-fold increase in their hypoglycaemic effect when compared with chitosan nanoparticles without HPMCP [68]. Self-assembled nanoparticles were developed by mixing the anionic poly- $\gamma$-glutamic acid ( $\gamma$-PGA) solution with the cationic chitosan solution in the presence of $\mathrm{MgSO}_{4}$ and sodium tripolyphosphate (TPP). TPP and sulphate salts were physically added to crosslink chitosan by ionic gelation, while physical gelation may occur between $\mathrm{Mg}^{+}$and the carboxylate ions on $\gamma$-PGA via an electrostatic interaction. Chitosan- $\gamma$-PGA nanoparticles remained intact within the $\mathrm{pH}$ range of 2.0-7.2; however, at lower $\mathrm{pH}$ values they disintegrated. The pharmacodynamics and pharmacokinetics of insulin were evaluated in a diabetic rat model and the relative bioavailability was 15\% [69]. For the further enhancement of bioavailability, two approaches were investigated: in the first, chitosan- $\gamma$-PGA nanoparticles were freeze-dried and placed in an enteric-coated capsule, while in the second, a penetration enhancer - diethylene triamine pentaacetic acid (DTPA) - was added. In both cases the bioavailability was approximately $20 \%$ [70,71].

The problem of the low solubility of chitosan in the neutral environment of the intestine was solved by synthesis of a partially quaternized derivative of chitosan - Trimethyl chitosan (TMC). TMC has good solubility and a permeation enhancing effect [72]. The targeting of trimethyl chitosan chloride to goblet cells was achieved through modification with a CSKSSDYQC (CSK) targeting peptide. The significant internalization of insulin via clathrinand caveolae-mediated endocytosis on goblet cell-like HT29-MTX cells results in a better hypoglycaemic effect with a 1.5-fold higher relative bioavailability compared with unmodified TMC nanoparticles [73]. Trimethyl chitosan-cysteine conjugate and N-(2hydroxyl) propyl-3-trimethyl ammonium chitosan were synthesized and demonstrated high mucoadhesion capability compared with TMC/insulin nanoparticles or native chitosan [74, 75]. Quaternized derivatives of chitosan have a high positive charge, which can easily 
interact with negatively-charged blood corpuscles, resulting in haemolysis and toxicity [76]. To overcome these problems, chitosan derivatives were modified with polyethylene glycol to reduce the interaction between the cationic polymers and cell membranes [77]. Chitosan was also modified with hydrophobic fatty acids, such as anacardic acid. Anacardoylated chitosan spontaneously formed nanoparticles in an aqueous insulin solution that sustained the release of insulin in the intestinal environment [78].

\subsubsection{Mechanisms of the absorption of nanoparticles}

The absorption of the nanoparticles was thoroughly reviewed by des Rieux [8]. A particle can traverse the intestinal epithelium by the paracellular (between cells) or transcellular route (through the cells). The transcellular route is the most common. With the transcellular transport of nanoparticles, the particles are taken up by cells through the endocytic process which takes place at the cell apical membrane - transported through the cells and released at the basolateral pole. Two types of intestinal cells are important in nanoparticle transcytosis: the enterocytes lining the gastrointestinal tract and the $M$ cells mainly located in Peyer's patches. The uptake of nanoparticles takes place by one of three endocytotic mechanisms: pinocytosis, macropinocytosis or clathrin-mediated endocytosis. Clathrin vesicles are for particles smaller than $150 \mathrm{~nm}$ while phagocytosis is for particulate matters of up to several $\mu \mathrm{m}$. The uptake of particles, microorganisms and macromolecules by $\mathrm{M}$ cells occurs by fluid phase endocytosis, adsorptive endocytosis and phagocytosis [8].

\subsubsection{Lipid-based systems}

Lipid-based delivery systems (LDS) range from simple oil solutions to complex mixtures of oils, surfactants, cosurfactants and cosolvents [79]. The bioavailability of several peptides was improved when incorporated into LDS - e.g., cyclosporine (Neoral $\left.{ }^{\circledR}\right)$. The enhancement in absorption was attributed to an increase in membrane permeability, the inhibition of efflux transporters, a reduction in cytochrome P450 enzymes, an increase in chylomicron production and lymphatic transport [80].

\subsubsection{Types}

The LDS investigated for the delivery of insulin are: multiple emulsions, microemulsions and solid in-oil-in water systems.

\subsection{Water-in-oil-in-water}

A water-in-oil-in-water $(\mathrm{W} / \mathrm{O} / \mathrm{W})$ emulsion has been proposed to protect peptides against proteolysis and enhance their absorption. Multiple emulsions containing unsaturated fatty acids (oleic acid, linoleic acid and linolenic acid) have been reported to enhance the ileal and colonic absorption of insulin without tissue damage [81]. The transport enhancement of the $\mathrm{W} / \mathrm{O} / \mathrm{W}$ emulsion prepared with octanoic acid triacylglycerol was found to be affected by the size of oil droplets. When the oil-droplet median was $2.3 \mu \mathrm{m}$, an earlier hypoglycaemic response was observed compared with a multiple emulsion, having a diameter of $3.8 \mu \mathrm{m}$. In contrast, the emulsion with a diameter of $0.7 \mu \mathrm{m}$ exhibited no effect [82]. 


\subsection{Microemulsions}

Microemulsions are clear, stable, isotropic mixtures of oil, water and surfactant, frequently in combination with a cosurfactant [83]. The average particle size of microemulsions falls in the range of 5-100 $\mathrm{nm}$; they are polydispersed in nature and the polydispersity decreases with decreasing particle size [84]. Insulin-loaded microemulsions were developed using didodecyldimethylammonium bromide as the surfactant, propylene glycol as the cosurfactant, triacetin as the oil phase and insulin solution as the aqueous phase. These microemulsions displayed a 10-fold enhancement in bioavailability compared with a plain insulin solution administered orally to healthy rats [85]. The improved oral bioavailability of the w/o microemulsion system was also shown for a lecithin-based microemulsion of rhinsulin [86]. On the other hand, Kraeling and Ritschel [87] found that the oral pharmacological availability of insulin microemulsions as compared with intravenous insulin in beagle dogs was $2.1 \%$, which further increased to $6.4 \%$ with the encapsulation of gelled microemulsions in hard gelatine capsules along with the protease inhibitor aprotinin and coating of the capsules for colonic release [87]. The improved oral delivery of insulin from a microemulsion system was also demonstrated by others [88]. A stable selfemulsifying formulation for the oral delivery of insulin was developed by Ma et al. [89]. It is composed of two non-ionic surfactants (polyethylene glycol-8-glycol octanoate/decanoate and polyglycerol-3 oleate). In diabetic beagle dogs, the bioavailability of this formulation was up to $15.2 \%$ at a dose of $2.5 \mathrm{IU} / \mathrm{kg}$ in comparison with the hypoglycaemic effect of native insulin $(0.5 \mathrm{IU} / \mathrm{kg})$ delivered by subcutaneous injection.

\subsection{Solid-in-oil-in water $(S / O / W)$ emulsions}

$\mathrm{S} / \mathrm{O} / \mathrm{W}$ emulsions were also developed for the delivery of insulin whereby insulin was converted into a lipophilic complex by coating with surfactant molecules and dispersed in an oil phase of oil in a water emulsion to form the S/O/W emulsion [90]. The stability of this system was enhanced by lyophilization [91].

\subsubsection{Mechanism of the absorption of lipid-based formulations}

Suggested mechanisms of intestinal drug absorption, using lipid-based formulations include: an increase in membrane fluidity facilitating transcellular absorption, the opening of the tight junctions to allow paracellular transport (mainly relevant for ionized drugs or hydrophilic macromolecules), the inhibition of P-glycoprotein and/or cytochrome P450 to increase intracellular concentration and residence time, and the stimulation of lipoprotein/ chylomicron production [92].

\section{Chitosan-fatty acid systems}

\subsection{Rationale}

Chitosan nanoparticles prepared by ionotropic gelation or polyelectrolyte complexation dissociate easily in an acidic medium. This might be related to the fact that both insulin and chitosan have net positive charges at $\mathrm{pH} 1.2$, that the columbic repulsive forces lead to the 
dissociation of the complex and that the free insulin is subjected to degradation. For example, nanoparticles prepared from chitosan and poly ( $\gamma$-glutamic acid) became unstable at $\mathrm{pH} 1.2$ and broke apart [93] and nanoparticles composed of chitosan and tripolyphosphate rendered the protein more susceptible to acid and enzymatic hydrolysis [94]. In the present investigation, we benefited from the advantages of polyelectrolyte complexation between chitosan and insulin, its formulation in an aqueous environment without the need for heat or an organic solvent, and the solution of the shortcomings of burst release by the dispersion of nanoparticles in an oily phase. The oily vehicle was intended to reduce proteolytic degradation and improve absorption $[95,96]$. In addition, the free chitosan amine groups may interact with any adjacent carboxylic acid groups of oleic acid, forming a protective hydrophobic coating layer at the surface of the dispersed phase, which may enhance stability in the GIT and promote lymphatic uptake. The particle size of the chitosan-oleic system is above $1 \mu \mathrm{m}$, due to the interaction. The reduction of the particle size of chitosan-oleic acid emulsion to nanosize was achieved by high pressure homogenization or else by the addition of surfactants. PEG-8 caprylic/capric glycerides (Labrasol) and polyglyceryl-6 dioleate were selected as surfactant and cosurfactant, respectively. Chitosan-insulin nanoparticles were solubilized in the inverted micelles. Chitosan plays an important role - as a matrix for nanoparticles and stabilizers of inverted micelles. In a previous work [97], we demonstrated the role of chitosan in the reduction of particle size of the w/o emulsion containing Labrasol, plurol oleique and oleic acid. This was attributed to the interaction of amine groups of chitosan with the surfactant-cosurfactant aggregates, resulting in the formation of a closer packing of surfactants at the interface, which leads to a reduction in particle size. This effect is more pronounced in 1:1 surfactant:cosurfactant rather than in 4:1 systems. Insulin is a water soluble protein that will be located inside the water droplets. Chitosan will be partly fixed near the surfactant head groups with the rest of it inside the water droplet. Interactions between chitosan, surfactants and insulin resulted in smaller microemulsion sizes [97]. Moreover, low molecular weight chitosans were chosen to prepare the nanoparticles, since their intestinal absorption is known to be significantly better than the high molecular weight candidates and showed a negligible cytotoxic effect on the Caco-2 cells [98].

The potential of chitosan-fatty acid or chitosan-fatty acid derivative nanoparticles as oral delivery carriers of insulin was investigated systematically.

\subsection{Chitosan-fatty acid nanocarriers' development}

Detailed descriptions of the compositions and preparation methods can be found in the relevant patents [99, 100]. Low molecular weight chitosans were obtained by the depolymerization of high molecular weight chitosan using $2 \mathrm{M}$ hydrochloric acid. The resulting fractions were characterized by Fourier transformed infrared spectroscopy (FTIR), differential scanning calorimetry (DSC), X-ray powder diffraction (XRPD), nuclear magnetic resonance (NMR) and dynamic light scattering (DLS). The polyelectrolyte complexation method was utilized to prepare insulin-chitosan nanocomplexes. Chitosan was dissolved in deionized water and its $\mathrm{pH}$ was adjusted to 5.5 using $0.2 \mathrm{M} \mathrm{NaOH}$. rh-insulin powder was 
dissolved in $0.1 \mathrm{M} \mathrm{HCl}$, followed by the addition of $1 \mathrm{M}$ Tris (hydroxymethyl)aminomethane buffer $\mathrm{pH}$ 7. Chitosan-insulin complexes were prepared by adding chitosan solution to an equal volume of insulin solution in a glass vial under gentle magnetic stirring, and incubating for a further 15 minutes at room temperature. The parameters affecting the encapsulation efficiency were investigated (final $\mathrm{pH}$ of the complex, molecular weight of chitosan, DDA of chitosan, initial concentration of chitosan and insulin, and chitosan: insulin ratio). A phase diagram was constructed and the results were used as guidance to select the suitable percentages of surfactants, oil and aqueous phases suitable for the nanoparticle dispersion system. The nanoparticle dispersion system was prepared by mixing two phases - the aqueous phase and the oily phase. The oily phase consists of Labrasol ${ }^{\circledR}$ and plurol oleique ${ }^{\circledR}$ at a fixed weight $(1 / 1)$ ratio and oleic acid. The aqueous phase composed of a chitosan-insulin complex. To prepare the dispersion system, $50 \mu \mathrm{l}$ of the aqueous phase was added to $2.5 \mathrm{~g}$ of the oily phase during mixing with a vortex mixer (VELP Scientifica, Europe) for $1 \mathrm{~min}$. at room temperature $\left(25^{\circ} \mathrm{C}\right)$. The preparation was characterized: viscosity, particle size, morphology and encapsulation efficiency were all determined. The chemical and immunological stabilities of insulin after entrapment into nanoparticles were studied. The suitability of the preparation to preserve insulin activity, to withstand gut enzymes and to maintain the stability of insulin upon storage was investigated [101]. The hypoglycaemic effect of the preparation after oral administration to streptozotocindiabetic rats was evaluated. The parameters that influence the pharmacological availability were characterized. The bioavailability of the preparation versus subcutaneous injection was calculated together with the pharmacokinetic parameters. Moreover, human studies were conducted where twenty-five healthy volunteers participated in five studies using a twophase, two-sequence crossover design with a washout period of one day [102]. Other chitosan fatty acid systems were also formulated, for example chitosan sodium lauryl sulphate nanoparticles [103] and chitosan-oleic acid nanoemulsion (particle size reduced by a high pressure homogenizer) and their hypoglycaemic effects were evaluated and compared to the chitosan-oleic acid-surfactants system.

\subsection{Results and discussion}

\subsubsection{Depolymerization and characterization of chitosan}

Most commercially available chitosans possess quite large M.wts. LMWCs are better amenable for a wide variety of biomedical applications due to their solubility in water [104106]. In addition, chitooligomers were found to be non-mutagenic and non-genotoxic when orally administered to mice [107]. To generate low molecular weight chitosans from high molecular weight candidates, hydrolysis by hydrochloric acid was adopted due to its practicability and reproducibility. IR spectrum spectroscopy demonstrated that there was no structure change during depolymerization. DDA was determined by NMR and it was about 99\%. [101]. The solubility of chitosan increased with decreasing molecular weight. Chitosan has a positive zeta potential and its value is affected by the $\mathrm{pH}$, molecular weight, DDA and concentration [108]. LMWCs with an average molecular weight of $13 \mathrm{KDa}$ and DDA 99\% were used for further studies. 


\subsubsection{Chitosan-insulin polyelectrolyte complexes (PECS)}

Insulin was first complexed with chitosan through the interaction of negatively charged insulin with positively charged chitosan to form PEC before incorporation into the oily vehicle. This is because chitosan has many beneficial effects, such as penetration enhancement. Chitosan was also found to stabilize insulin when incubated at $50 \pm 1{ }^{\circ} \mathrm{C}$ while shaking at 100 strokes/min in a water bath [101]. As shown in Figure 3, the insulin solution was almost degraded while the chitosan-insulin complex protected the insulin from degradation for at least $24 \mathrm{~h}$. In addition, chitosan has a role in protecting insulin from those enzymes present in the small intestine. This was reflected in the partial protection of insulin from pancreatin, as depicted in Figure 4, and the protection increases with the increase of the chitosan ratio. Moreover, chitosan may also protect insulin from destabilization at the oil/water interface when the PEC was dispersed in the oily vehicle. The PEC formation process is influenced by a variety of parameters, including the system $\mathrm{pH}$, chitosan molecular weight and DDA. The most important factor appears to be the system $\mathrm{pH}[101]$.

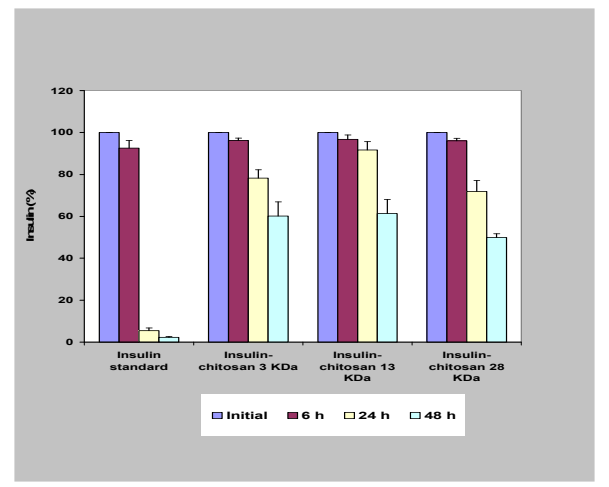

Figure 3. Effect of the temperature and shaking on the stability of the insulin

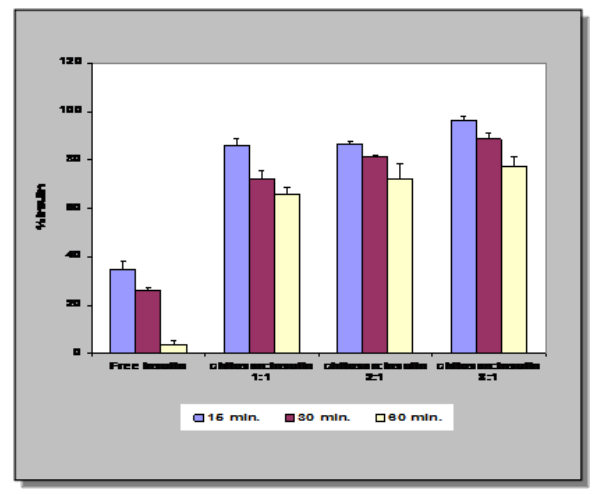

Figure 4. Effect of the chitosan:insulin ratio on the pancreatic degradation of insulin 


\subsubsection{Oily nanosystem preparation}

Chitosan-insulin PECs were solubilized in an oily vehicle composed of a surfactant Labrasol, cosurfactant Plurol Oleique and an oily vehicle oleic acid. We attempted to formulate an oral insulin delivery system that combined the advantages of nanoencapsulation and the use of an oily vehicle. The nanoparticles were expected to translocate the intestinal epithelium, while the oily vehicle was intended to reduce proteolytic degradation and improve permeability $[109,110]$. In addition, Labrasol and oleic acid are known penetration enhancers [111, 112]. Our expectation is that part of the chitosan will rest inside the water droplet of the inverted micelles where it forms PEC with insulin while the other part projecting near the surfactant head groups where it interacts with surfactants stabilizes the w/o microemulsion and resulted in smaller microemulsion sizes [97]. Chitosan at pH 6 will also interact with oleic acid to coat the particles with a hydrophobic layer. This interaction was studied by molecular mechanics, as illustrated in Figure 5. The structure of chitosan $13 \mathrm{KDa}$, oleic acid and chitosan-oleic acid
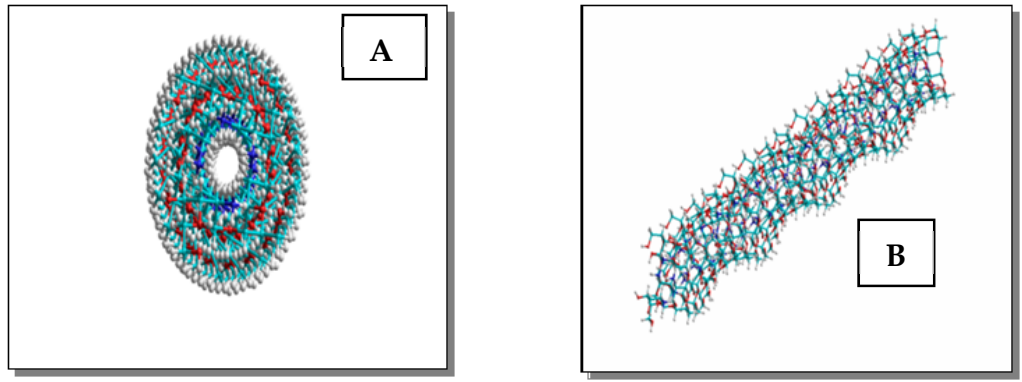

(a)

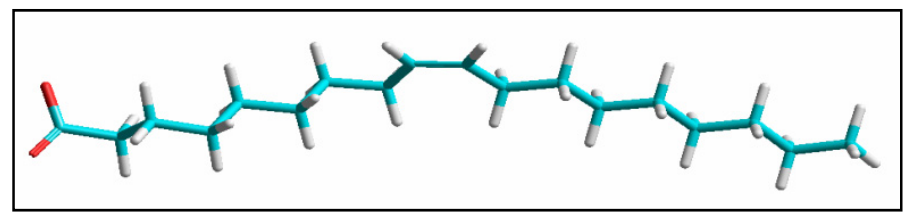

(b)
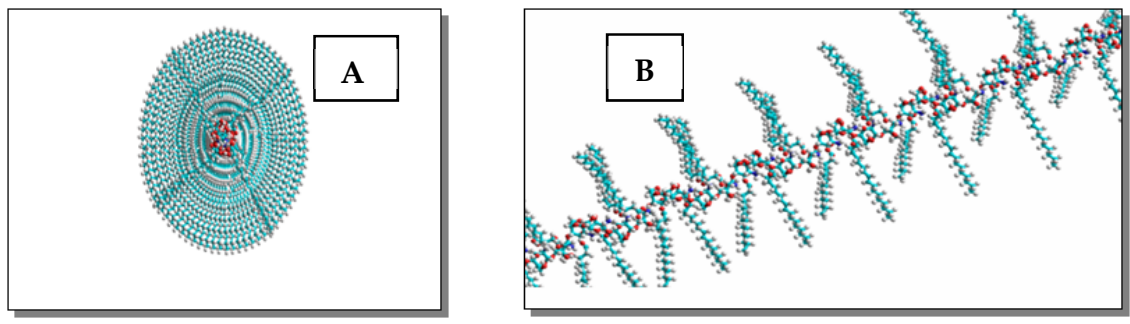

(c)

Figure 5. a. Top view (A) and side view of chitosan (B); b. The computed molecular geometries of oleic acid; c. Top view (A) and side view of the chitosan-oleic acid complex 
complex, which were built up in Hyperchem ${ }^{\circledR}$, was shown in Figures 5.a, b and c, respectively. The conformation of individual chitosan and oleic acid was the same as the complex.

It is obvious that the outer structure of the complex was hydrophobic due to presence of oleic acid while chitosan was embedded inside the structure. This is consistent with the immiscibility of the complex with water. The binding energy of the resulting chitosan oleic acid complex is calculated according to the following equation:

$$
\begin{gathered}
\text { E binding }=\mathrm{E} \text { complex }-(\text { Eoleate }+ \text { Echitosan }) \\
\mathrm{E}_{\text {complex }}=-539.94 ; \mathrm{E}_{\text {oleic }}=2131.64 ; \mathrm{E}_{\text {chitosan }}=4526.58 ; \mathrm{E} \text { binding }=-7198.2 \mathrm{kcal} / \mathrm{mol} .
\end{gathered}
$$

The value of the binding energy suggested a high degree of interaction between chitosan and oleic acid. The chitosan-oleic acid interaction was also studied using statistical design [108]. The effects of three formulation variables (the aqueous chitosan solution to oleic acid ratio, the chitosan molecular weight, and the degree of deacetylation of chitosan) on the viscosity of the system and the length of the emulsified layer (\%) were studied in a conventional $2^{3}$ factorial design. It was found that chitosan-oleic acid interaction is significantly influenced by $\mathrm{pH}$. At a $\mathrm{pH}$ of around 6.5 , chitosan is almost $50 \%$ ionized ( $\mathrm{pKa}$ $\mathrm{NH}_{3} / \mathrm{NH}_{2} \sim 6.5$ ) and the ionized amine groups in chitosan will interact with the carboxylate ion of oleic acid. However, at $\mathrm{pH} 1.5$, chitosan will be available as chitosan hydrochloride, and so no interaction was observed. $50 \%$ oleic acid and $50 \%$ chitosan aqueous solution ( $2 \%$ ) at different $\mathrm{pH}$ were mixed and their viscosities were determined, as depicted in Figure 6. A sharp increase in viscosity was noticed when the $\mathrm{pH}$ of chitosan was $\geq 5.5$. This indicates that the rheological properties of this dispersion were notably influenced by other factors apart from the disperse phase volume fraction - such as the interaction between chitosan and oleic acid. These results were consistent with the surface tension measurements of the chitosan-oleic acid system [97].

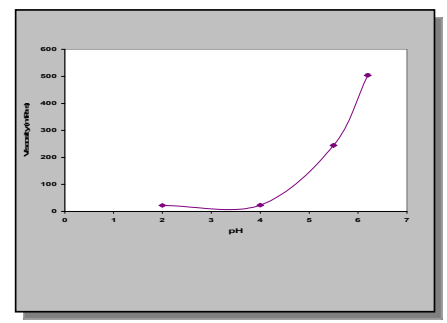

Figure 6. The effect of the $\mathrm{pH}$ of chitosan on the viscosity of oleic acid chitosan dispersions

\subsubsection{Oily nanosystem characterization}

The mean particle size was determined by dynamic light scattering - it was $111 \pm 6.9 \mathrm{~nm}$ and showed a unimodal particle size distribution. The particle size is affected by the molecular weight of chitosan, as shown in Table 6 . An increase in the molecular weight of the chitosan polymer led to an increase in the dispersed phase particle size. The particles' 
shapes were assessed by a transmission electron microscope (TEM) and it was spherical, as depicted in Figure 7. The viscosity of the nanosystem was measured by a Vibro viscometer it was $52.25 \pm 2.6 \mathrm{mPa}$ s. Neither the particle size nor the viscosity of the nanosystem changed upon storage at 4 or $25{ }^{\circ} \mathrm{C}$ for one month, indicating the physical stability of the nanosystem. The preparation procedure is mild and the insulin is chemically and immunologically stable, as illustrated by RP-HPLC and ELISA, respectively. About $90 \%$ of the insulin was recovered from the preparation after incubation with pepsin, indicating the protective ability of the preparation for insulin under conditions simulating the gastric environment [97]. In addition, short term chemical stability demonstrates that the chemical stability of the insulin was maintained for at least 30 days of storage at 4 and $25{ }^{\circ} \mathrm{C}$, according to the HPLC method. Moreover, the biological activity was reserved after one month at storage temperatures of 4 and $25^{\circ} \mathrm{C}$.

\begin{tabular}{|c|c|}
\hline $\begin{array}{c}\text { Chitosan } \\
\text { M.wt (KDa) }\end{array}$ & $\begin{array}{c}\text { Mean diameter } \\
(\mathrm{nm}) \pm \mathrm{SD}\end{array}$ \\
\hline 3 & $79 \pm 2.5$ \\
\hline 13 & $111 \pm 6.9$ \\
\hline 30 & $205 \pm 2.6$ \\
\hline
\end{tabular}

Table 6. The mean diameter of the oily nanosystem prepared from chitosans with different molecular weights

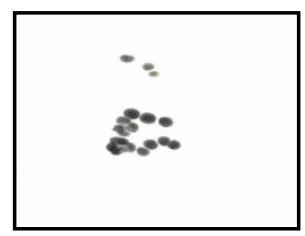

Figure 7. TEM image of the oily nanosystem

\subsubsection{In vivo studies}

The preliminary screening of the biological activity of nanoparticles prepared from different grades of chitosan (different molecular weights and DDA) and administered orally to STZ diabetic rats revealed a maximum effect with nanoparticles prepared from chitosan with a molecular weight of $13 \mathrm{KDa}$ and DDA 99\%. Figure 8 illustrates changes in the plasma glucose levels after the oral administration of the nanoparticles prepared from chitosan with a molecular weight of $13 \mathrm{KDa}$ and DDA 99\%. As expected, the insulin oral solution showed no hypoglycaemic effect compared to the control group $(\mathrm{P}>0.05)$. In contrast, the blood glucose levels of the rats decreased remarkably after the oral administration of insulinloaded nanosystem, achieving a significant decrease at $3 \mathrm{~h}$ when compared with the control group $(\mathrm{P}<0.05)$. More interestingly, the hypoglycaemic effect was maintained without recovery at the baseline for $12 \mathrm{~h}$. A pharmacological availability value of $29 \%$ was obtained for the dose $5 \mathrm{IU} / \mathrm{kg}$. An explanation of this positive behaviour of the oily nanosystem could 
be put forward in terms of the demonstrated ability of oily preparations to make the entrapped insulin more stable and protect it from degradation in the harsh conditions of the gastrointestinal tract as well as enhance its intestinal absorption.

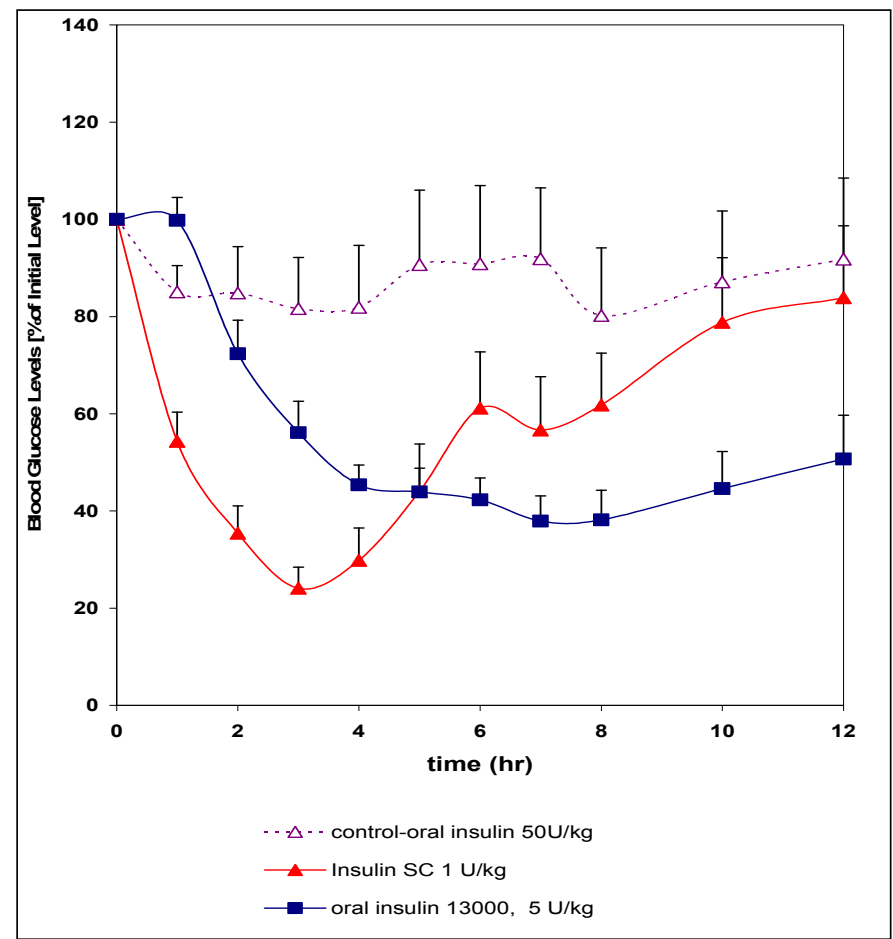

Figure 8. Changes in blood glucose level versus time profiles after a single oral administration of the oily dispersion of chitosan-insulin nanoparticles given at a dose level $5 \mathrm{IU} / \mathrm{Kg}$ (, to STZ-diabetic rats compared to a free insulin solution given orally $(50 \mathrm{IU} / \mathrm{Kg})$ as a control group $(\Delta)$ and a subcutaneous injection of a free insulin solution $(1 \mathrm{IU} / \mathrm{Kg})(\mathbf{4}$ The results are expressed as the mean \pm S.E.M $(\mathrm{n}=12$ per group)

A concomitant increase in plasma insulin levels was observed after the oral administration of the $5 \mathrm{IU} / \mathrm{kg}$ of insulin-loaded oily nanosystem to diabetic rats, as depicted in Figure 9. The pharmacokinetic parameters were determined based on the insulin concentration plasma profiles of Figure 9, as shown in Table 7. The subcutaneous injection group exhibited a rapid increase in serum rh-insulin concentration up to $279.2 \mu \mathrm{IU} / \mathrm{ml}$ over $30 \mathrm{~min}$ of administration. Meanwhile, the intragastric administration of $5 \mathrm{IU} / \mathrm{kg}$ of nanoparticles exhibited slower absorption and sustained elimination, reaching a maximum after $2 \mathrm{~h}(102.22 \mu \mathrm{IU} / \mathrm{ml})$. Moreover, the serum rh-insulin levels of the nanoparticle group were significantly different from that of the control group $(\mathrm{P}<0.001)$. The AUC $0-12$ of orally administered nanoparticles was $664.99 \mu \mathrm{g} \mathrm{hr} / \mathrm{ml}$ for the $5 \mathrm{IU} / \mathrm{kg}$ dose and $626.02 \mu \mathrm{g} \mathrm{hr} / \mathrm{ml}$ for the $1 \mathrm{IU} / \mathrm{kg}$ subcutaneous rh-insulin dose. The corresponding relative bioavailability was calculated to be $21.24 \%$ [108]. 
These results clearly show that rh-insulin absorption was markedly enhanced by the nanoparticles dispersed in oily vehicle. As a proof of concept, early clinical trials have been performed by Badwan et al. [102]. The pharmacokinetic, pharmacodynamic and absorption kinetics of insulin-loaded oily nanosystem preparations of different particle sizes (57-220 $\mathrm{nm}$ ) were compared with those of subcutaneous formulation in 25 healthy individuals using a euglycaemic clamp technique. The dose used was either 1, 2 or $3 \mathrm{IU} / \mathrm{Kg}$. The effective permeability ratio $\left(\right.$ Peff $^{*}$ ) was higher for preparations with a particle size of $57 \mathrm{~nm}$ than for those with a larger particle size. The preparation with the lowest particle size also exhibited the highest ratio in the dimensional analysis of the glucose infusion rate as a pharmacodynamic effect, while the other insulin formulations that were tested showed similar ratio profiles. The calculated intestinal permeability coefficients $(\times 10-4)$ of the insulin best test and reference formulations were 0.084 and $0.179 \mathrm{~cm} / \mathrm{sec}$ respectively. The total fraction of the insulin dose absorbed ( $\mathrm{Fa}$ ) for the test and reference products were $3.0 \%$ and $19 \%$ respectively. From these small studies, it was concluded that oral insulin bioavailability is promising for the development of oral insulin products.

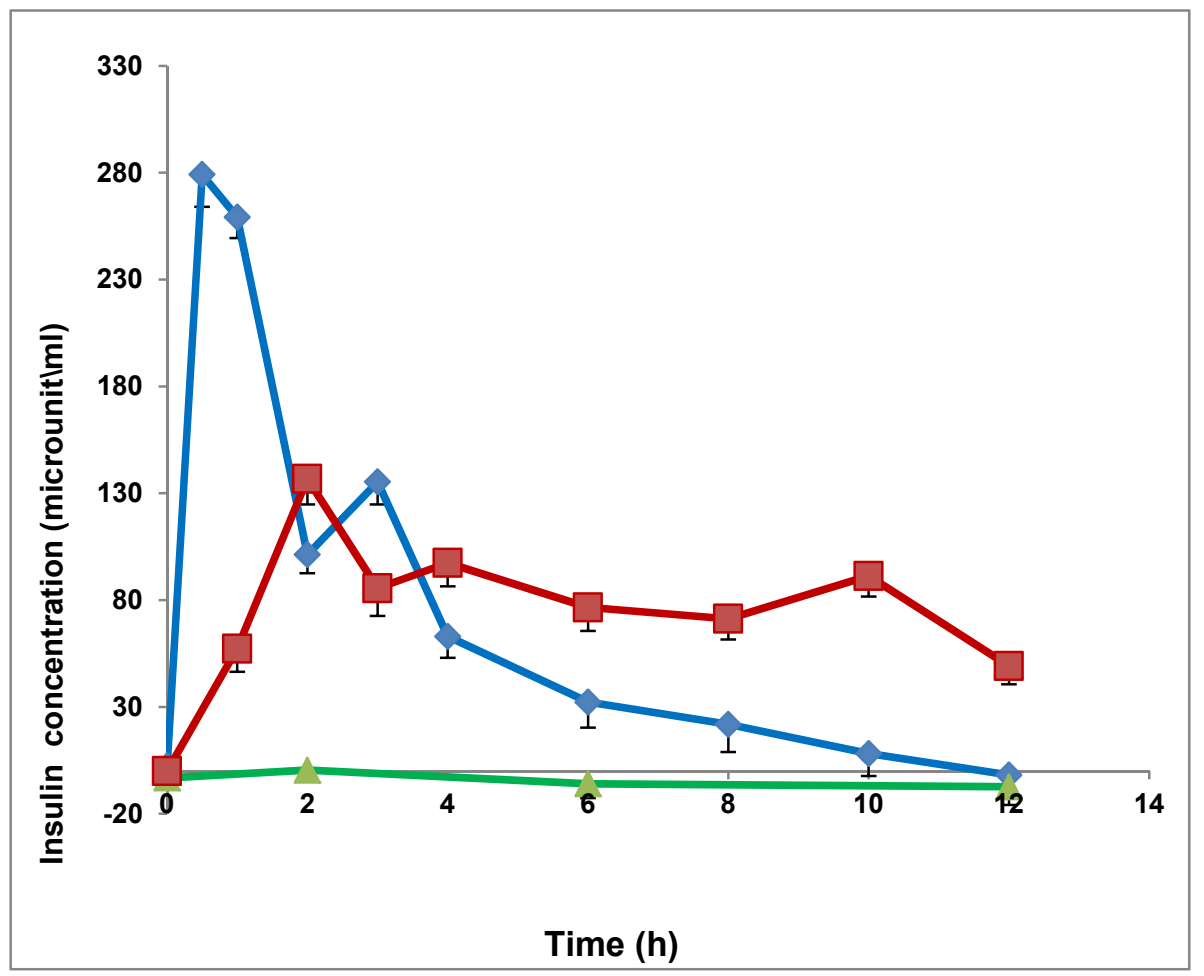

Figure 9. Insulin plasma levels profile after a single oral administration of the oily dispersion of chitosan-insulin nanoparticles $(5 \mathrm{IU} / \mathrm{Kg})(\mathbf{G}$ in fasted diabetic rats compared to the subcutaneous injection of free insulin ( $1 \mathrm{IU} / \mathrm{Kg}$ ) ( $\mathbf{4}$ and an oral insulin solution $(50 \mathrm{IU} / \mathrm{kg}$ ) as a control ( $\mathbf{4}$. The results are expressed as the average of the three independent experiments $(n=18)$ 


\begin{tabular}{|c|c|c|c|c|c|}
\hline Preparation & $\begin{array}{c}\mathrm{Cmax} \\
{[\mu \mathrm{g} / \mathrm{ml}]}\end{array}$ & Tmax [hr] & MRT [hr] & $\begin{array}{c}\text { AUC0-12 } \\
{[\mu \mathrm{g} \mathrm{hr} / \mathrm{ml}]}\end{array}$ & $\mathrm{F} \%$ \\
\hline $\begin{array}{c}\text { S.C injection } \\
(\mathbf{1} \text { IU/kg) }\end{array}$ & $\mathbf{2 7 9 . 1 9}$ & $\mathbf{0 . 5}$ & & 626.02 & \\
\hline $\begin{array}{c}\text { Oral formula } \\
(\mathbf{5} \mathrm{IU} / \mathrm{kg})\end{array}$ & $\mathbf{1 0 2 . 2 2}$ & $\mathbf{2}$ & $\mathbf{6 . 7 2}$ & 664.99 & $21.24 \%$. \\
\hline
\end{tabular}

Table 7. Pharmacokinetic parameters derived from the plasma level vs. the time profile for insulin

Other chitosan fatty-acid systems were also developed and compared to the above mentioned system. For example, chitosan-sodium lauryl sulphate nanoparticles dispersed in an aqueous vehicle elicited a pharmacological response after oral administration [103]. However, the pharmacological availability was poor $-1.1 \%$ versus $29 \%$ for nanoparticles dispersed in an oily vehicle. Another system was developed by dispersing PEC in oleic acid and the particle size was reduced using a high pressure homogenizer. The oral administration of this preparation resulted in a pronounced effect $(\mathrm{P}<0.001)$ after $12 \mathrm{~h}$ of administration and the effect was sustained for $24 \mathrm{~h}$ (Figure 10). This indicates that chitosan-oleic acid nanoparticles were slowly absorbed in comparison with the preparation containing surfactants. This may be due to the permeation enhancing effect of surfactants [108]

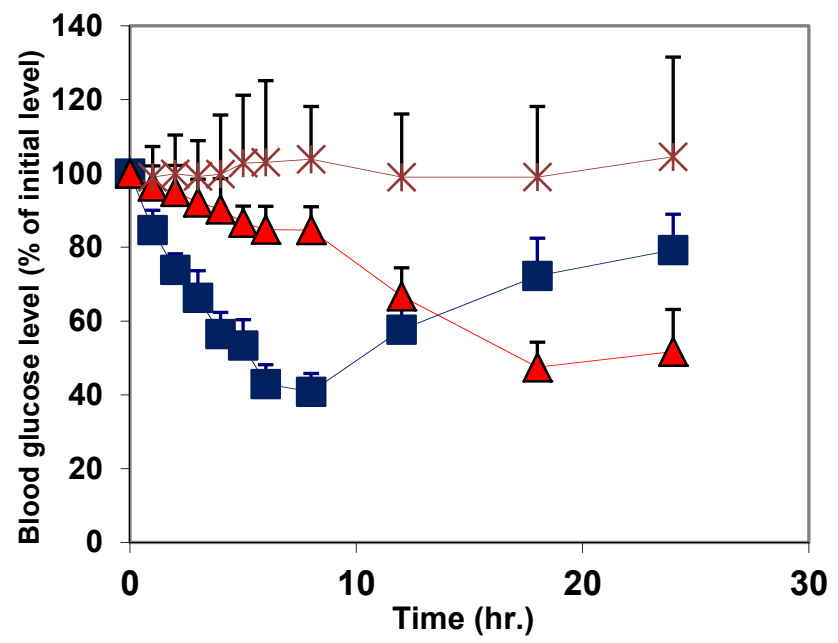

Figure 10. Changes in blood glucose level versus time profiles after a single oral administration of an oily dispersion of a chitosan-insulin oily nanosystem containing surfactant given at a dose level of 5 $\mathrm{IU} / \mathrm{Kg}$ ( to STZ-diabetic rats compared to a chitosan-insulin oily nanosystem without surfactant (4 The control was given a placebo (a formula containing all excipient) $(x)$. The results are expressed as the mean \pm S.E.M $(n=12$ per group)

In conclusion, the use of the combination strategy of nanoencapsulation and an oily vehicle has shown considerable improvement in insulin delivery along the following lines: 
1) A significant hypoglycaemic action with a maximum pharmacological availability of $29.0 \%$ was obtained; 2) The relative bioavailability was $21.2 \%$; 3) The antidiabetic activity was prolonged for many hours; 4) The insulin in the preparation was chemically and biologically stable for a period of one month at storage temperatures of $4{ }^{\circ} \mathrm{C}$ and $25^{\circ} \mathrm{C}$. 5). The system could be considered as a platform technology for the delivery of other peptides, such as calcitonin.

\section{Oral insulin formulations in clinics}

Oral systems in different clinical phases and the companies who have invested on them were listed in Table 8. The modification of proteins' structures by the attachment of proper moieties which alter their biopharmaceutical properties have been investigated by Biocon (Bangalore, India) and Nobex Corporation (Research Triangle Park, NC, USA). Nobex developed an orally active amphiphilic human insulin analogue, methoxy (polyethylene glycol) hexanoyl human recombinant insulin. Biological activity is retained and this compound is readily absorbed from the gastrointestinal tract. The effect of a single oral dose of hexyl-insulin monoconjugate 2 (HIM2) on the rate of whole-body glucose disposal (Rd) and endogenous glucose production (EGP) was investigated in healthy non-diabetic subjects using a euglycaemic clamp technique. Oral HIM2 suppresses EGP and increases tissue $R \mathrm{~d}$ in a dose-dependent manner. The effects of HIM2 on EGP and Rd persisted for $240 \mathrm{~min}$. In patients with type 1 diabetes mellitus, a statistically significant effect of HIM2 on glucose excursion was observed [113]. The further development of the product was abandoned by the company. Biocon modified the hexyl insulin monoconjugate 2 (HIM2) developed by the Nobex Corporation. Conjugation with poly (ethylene glycol) improves the protein solubility, stability from enzymatic degradation and intestinal absorption [114]. The modified insulin (IN-105) was formulated as tablets and has a short duration of action (1.5-2 h). It was found that IN-105 reduced postprandial glucose excursion by $2 \mathrm{~h}$ in a dosedependent manner and that it was readily tolerated by patients [115]. However, in Phase III studies, IN-105 did not meet the target of lowering the level of glycated haemoglobin by $0.7 \%$ compared to a placebo, as announced by the company. The level of glycated haemoglobin in the body is an indication of the effectiveness of a drug in controlling blood sugar levels. In contrast, the noncovalent interaction of macromolecules with small hydrophobic organic compounds, SNAC (n-(8-[2-hydroxybenzoyl]-amino) caprylic acid) and 5-CNAC (N-(5-chlorosalicyloyl)-8-aminocaprylic acid), was the technology developed by Emisphere's Eligen ${ }^{\mathrm{TM}}$. As a result of this interaction, the lipophilicity and absorption of the macromolecules increases and this is reflected in the rapid onset of action (about 10 minutes). Emisphere's oral insulin product was well tolerated and improved both glycaemic control and insulin sensitivity. However, a high dose (40 mg/day) is needed to decrease $\mathrm{HbA1c}$ significantly after 3 months of therapy [116]. ORMD 0801 is a capsule formulation of insulin developed by Oramed Pharmaceuticals (USA). An omega-3 fatty acid (carrier), a soya bean trypsin inhibitor (protease inhibitor) and sodium EDTA (absorption enhancer) were selected as adjuvants to protect the insulin from the harsh environment of the gastrointestinal tract and enhance its transport across the intestinal mucosa. ORMD is an 
intermediate insulin product with a duration of action of 5-6 h. This product demonstrated improved absorption, as indicated by a $28 \%$ increase in post-prandial serum insulin and it is well tolerated by patients [117]. However, the onset of action is delayed by $2 \mathrm{~h}$, which may be due to the enteric coating of the capsules. Another capsule formulation (Capsulin) was developed by Diabetology (Jersey, UK). The capsule contains a mixture of penetration enhancers and solubilizers which are generally considered to be safe. The administration of the oral insulin Capsulin preparation to sixteen persons with type 2 diabetes demonstrated a significant hypoglycaemic action over a period of $6 \mathrm{~h}$ and was associated with only a small increase in circulating plasma insulin concentrations. Significant falls in HbA1c, weight and triglycerides were also observed [118].

\begin{tabular}{|c|c|c|c|c|}
\hline Technology & Example & Company & $\begin{array}{c}\text { Current } \\
\text { status }\end{array}$ & Ref \\
\hline $\begin{array}{c}\text { Chemical } \\
\text { modification }\end{array}$ & $\begin{array}{c}\text { Hexyl-insulin monoconjugate-2 } \\
\text { (HIM2) }\end{array}$ & Nobex corporation & Phase II & [113] \\
\hline $\begin{array}{c}\text { Chemical } \\
\text { modification }\end{array}$ & IN-105 & Biocon & Phase III & [115] \\
\hline $\begin{array}{c}\text { Delivery agent } \\
\text { Sodium N-[8-(2-hydroxybenzoyl) } \\
\text { amino] carpylate (SNAC) }\end{array}$ & Emisphere & Phase II & {$[116]$} \\
\hline $\begin{array}{c}\text { Soft-gel capsule with } \\
\text { enhancers }\end{array}$ & Oramed insulin capsule & Oramed & Phase II & [117] \\
\hline $\begin{array}{c}\text { Absorption enhancers } \\
\text { (Axcess } \\
\text { technology) }\end{array}$ & Capsulinery & $\begin{array}{c}\text { Diabetology (Jersey, } \\
\text { UK) }\end{array}$ & Phase II & {$[118]$} \\
\hline
\end{tabular}

Table 8. Systems currently being studied for the oral delivery of insulin

\section{Conclusions and prospects for further investigations}

Oral delivery is a physiological route for insulin administration. Improved disease management, the enhancement of patient compliance and the reduction of long-term complications of diabetes could be achieved by oral application. However, the challenges for developing oral insulin dosage forms are significant. A number of reports have appeared in the literature seeking to enhance insulin delivery via the oral route; however, the bioavailability in humans has not exceeded 10\%. Most systems evaluated the pharmacodynamics and pharmacokinetics of oral insulin preparations on animal models. However, a few reports studied absorption mechanisms. The absorption of insulin is the major obstacle. Therefore, more focus should be directed on studying the very small details of absorption, especially with the development of many instrumental technologies that will help in this area. Nanotechnology will contribute largely to the success of oral insulin delivery. The investigators should plan to search for safer, simpler and scalable methods using biologically acceptable polymers. Nowadays, researchers from both academia and industrial fields work on oral insulin. With these efforts, the dream of oral insulin will become real in the near future. 


\section{Nomenclature}

$\mathrm{Da}$

$\mathrm{KDa}$

HDV

PCL

PLGA

PL

PACA

PEG

LMWC

HMWC

DDA

M.wt

HPMCP

$\gamma$-PGA

TPP

TMC

LDS

SLN

GIT

rh-insulin

WGA

FTIR

DSC

XRPD

NMR

DLS

RP-HPLC

ELISA

TEM

PECs

AE

SLS

LDS

BSA

SGF

SIF

$\mathrm{W} / \mathrm{O}$

$\mathrm{O} / \mathrm{W}$

$\mathrm{W} / \mathrm{O} / \mathrm{W}$

$\mathrm{S} / \mathrm{O} / \mathrm{W}$

RSD
Dalton

Kilodalton

Hepatic directed vesicles

poly $\varepsilon$-caprolactone

Poly (lactic-co-glycolic acid)

Polylactides

Poly (alkyl cyanoacrylate)

Polyethylene glycol

Low molecular weight chitosan

High molecular weight chitosan

Degree of deacetylation

Molecular weight

Hydroxypropylmethylcellulose phthalate

poly- $\gamma$-glutamic acid

Tripolyphosphate

Trimethyl chitosan

Lipid-based delivery systems

Solid lipid nanoparticles

Gastrointestinal tract

Recombinant human insulin

Wheat germ agglutinin binds

Fourier Transformed Infrared Spectroscopy

Differential Scanning Calorimetry

X-Ray Powder Diffraction

Nuclear magnetic resonance

Dynamic light scattering

Reversed-phase high performance liquid chromatography

Enzyme-linked immunosorbent assay

Transmission electron microscope

Protein Polyelectrolyte Complexes

Association efficiency

Sodium lauryl sulphate

Lipid-based delivery systems

Bovine serum albumin

Simulated gastric fluid

Simulated intestinal fluid

Water in oil

Oil in water

Water-in-oil-in-water

Solid-in-oil-in water

Relative standard deviation 


$\begin{array}{ll}\text { s.c. } & \text { Subcutaneous } \\ \text { PA } & \text { pharmacological availability } \\ \text { RBA } & \text { Relative bioavailability } \\ \text { STZ } & \text { Streptozotocin } \\ \text { Tmax } & \text { the time taken to reach the plasma peak level } \\ \text { Cmax } & \text { The plasma peak level } \\ \text { MRT } & \text { Mean residence time } \\ \text { AUMC } & \text { Area under the first moment curve } \\ \text { AUC } & \text { Area under the curve } \\ \text { F\% } & \text { Relative bioavailability } \\ \text { AAC } & \text { Area above the curve } \\ \text { ANOVA } & \text { analysis of variance } \\ \text { MSE } & \text { Standard error of the mean } \\ P & \text { probability value } \\ \text { Tm } & \text { Melting temperature } \\ \text { GIT } & \text { Gastrointestinal tract } \\ \text { Rd } & \text { Rate of whole-body glucose disposal } \\ \text { EGP } & \text { endogenous glucose production }\end{array}$

\section{Author details}

Amani M. Elsayed

Department of Pharmaceutics, Faculty of Pharmacy, Taif University, Taif, Saudi Arabia

\section{Acknowledgement}

The experimental work was carried out and financially supported by the Jordanian Pharmaceutical Manufacturing Company, Naor-Jordan. Dr. Adnan Badwan for his constructive comments and Dr. Mayyas El-Remawi for his revision of the manuscript.

\section{References}

[1] Beals J, Brader M, De Felippis M, Kovach P. Insulin. In: Crommelin D, Sindelar R. (2 ${ }^{\text {nd }}$ ed) Pharmaceutical biotechnology. London: Taylor and Francis group; 2002. 231-242.

[2] Whittingham J, Scott D, Chance K, Wilson A, Finch J, Brange J, Dodson G. Insulin at pH 2: structural analysis of the conditions promoting insulin fiber formation. J. Mol. Biol. 2002; 318: 479-490.

[3] Chien Y . Human insulin: Basic sciences to therapeutic uses. Drug Dev. Ind. Pharm. 1996; 22: 753-789.

[4] Nordestgard B, Agerholm-Larsen B, Stender S. Effect of exogenous hyperinsulinaemia on atherogenesis in cholesterol-fed rabbits. Diabetologia 1997; 40: 512-520.

[5] Iyer H, Khedkar A. Verm M. Oral insulin - a review of current status. Diabetes, Obesity and Metabolism. 2010; 12: 179-185. 
[6] Arbit E. The physiological rationale for oral insulin administration. Diabetes Tech. \& Therap. 2004; 6: 510-517.

[7] Geho W. Hepatic-directed vesicle insulin: A review of formulation development and preclinical evaluation. Journal of Diabetes Science and Technology. 2009; 3 (6): 1451-1459.

[8] des Rieux A, Fievez V, Garinot M, Schneider Y, Preat, V. Nanoparticles as potential oral delivery systems of proteins and vaccines: a mechanistic approach. J. Control Release. 2006; 116: 1-27.

[9] TenHoor C, Dressman J. Oral absorption of peptides and proteins. S T P Pharma Sci. 1992; 2: 301-312.

[10] Aoki Y, Morishita M, Takayama K. Role of the mucous/glycocalyx layers in insulin permeation across the rat ileal membrane. Int. J. Pharm. 2005; 297: 98-109.

[11] Bilati U, Allemann E, Doelker E. Strategic approaches for overcoming peptide and protein instability within biodegradable nano- and microparticles. Eur. J. Pharm. Biopharm. 2005; 59: 375-388.

[12] Brange J, Langkjaer L, Havelund S, Hougaard P. Chemical stability of insulin. 2. Formation of higher molecular weight transformation products during storage of pharmaceutical preparations. Pharm. Res.1992; 9: 727-734.

[13] Brange J, Hallund O, Sorensen E. Chemical stability of insulin. 5. Isolation, characterization and identification of insulin transformation products. Acta Pharm. Nord. 1992; 4: 223-232.

[14] Ashada H, Douen T, Mizokoshi Y, Fujita T, Murakami M, Yamamoto A, Muranishi S. Absorption characteristics of chemically modified insulin derivatives with various fatty acids in the small and large intestine. J. Pharm. Sci. 1995; 84: 682-687.

[15] Ziv E, Lior O, Kidron M. Absorption of protein via the intestinal wall. A quantitative model. Biochem. Pharmacol. 1987; 36: 1035-1039.

[16] Kisel M, Kulik L, Tsybovsky I, Vlasov A, Kholodova, Zabarovskaya Z. Liposomes with phosphatidylethanol as a carrier for oral delivery of insulin: studies in the rat. Int. J. Pharm. 2001; 216, 105-114.

[17] Scott-Moncrieff J, Shao Z, Mitra, K. Enhancement of intestinal insulin absorption by bile salt-fatty acid mixed micelles in dogs, J Pharm Sci. 1994; 83: 1465-1469.

[18] Silva-Cunha A, Chéron J, Puisieux F, Seiller M. W/O/W multiple emulsions of insulin containing a protease inhibitor and an absorption enhancer: preparation, characterization and determination of stability towards proteases in vitro. Int. J. Pharm. 1997; 158: 79-89.

[19] Kim B-Y, Jeonga J, Parkb K, Kim J-D. Bioadhesive interaction and hypoglycemic effect of insulin-loaded lectin-microparticle conjugates in oral insulin delivery system, J. Control. Release 2005; 102: 525-538.

[20] Sarmento B, Martins S, Rebeiro A, Veiga F, Neufeld R, Ferreira D. Development and comparison of different nanoparticulate polyelectrolyte complexes as insulin carriers, Int. J. Peptide Res. Therap. 2006; 12: 131-138.

[21] Xiong X, Li Y, Li Z, Zhou C, Tam K, Liu Z, Xie G. Vesicles from Pluronic/poly(lactic acid) block copolymers as new carriers for oral insulin delivery, J. Control Release 2007; 120: 11-17. 
[22] Almeida A, Souto E. Solid lipid nanoparticles as a drug delivery system for peptides and proteins. Advanced Drug Delivery Reviews 2007; 59: 478-490.

[23] Niu M, Lua Y, Hovgaard L, Guan P, Tan Y, Lian R, Qi J, Wu W. Hypoglycemic activity and oral bioavailability of insulin-loaded liposomes containing bile salts in rats: The effect of cholate type, particle size and administered dose. European Journal of Pharmaceutics and Biopharmaceutics doi:10.1016/j.ejpb.2012.02.009

[24] Sarmento B, Martins S, Ferreira D, Souto E. Oral insulin delivery by means of solid lipid nanoparticles. International Journal of Nanomedicine 2007; 2(4): 743-749.

[25] Liu J, Gong T, Wang C, Zhong Z, Zhang Z. Solid lipid nanoparticles loaded with insulin by sodium cholate phosphatidylcholine-based mixed micelles: Preparation and characterization. International Journal of Pharmaceutics 2007; 340: 153-162.

[26] Fonte P, Andrade F, Arau' jo F, Andrade C, Neves J, Sarmento B. Chitosan-Coated Solid Lipid Nanoparticles for Insulin Delivery. Methods Enzymol. 2012; 508: 295-314.

[27] Gabor F, Wirth M, Jurkovich B, Theyer G, Walcher G, Hamilton G. Lectin-mediated bioadhesion: proteolytic stability and binding characteristics of Wheat germ agglutinin and Solanum tuberosum lectin on Caco-2, HT-29 and human colonocytes. J. Control. Rel. 1997; 49: 27-37.

[28] Wirth M, Hamilton G, Gabor F. Lectin-mediated drug targeting: quantification of binding and intemalization of wheat germ agglutinin and solanum tuberosum lectin using Caco-2 and HT-29 cells. J. Drug Targeting 1998; 6: 95-104.

[29] Zhang N, Ping Q, Huang, Wenfang X. Lectin-modified solid lipid nanoparticles as carriers for oral administration of insulin. International Journal of Pharmaceutics 2006; 327: 153-159.

[30] Reis C, Neufeld R, Ribeiro A, Veiga F. Nanoencapsulation I. Methods for preparation of drug-loaded polymeric nanoparticles. Nanomedicine 2006; 2: 8-21.

[31] Yang J, Sun H, Song C. Preparation, characterization and in vivo evaluation of $\mathrm{pH}-$ sensitive oral insulin-loaded poly(lactic-coglycolicacid) nanoparticles. Diabetes, Obesity and Metabolism 2012; 14: 358-364.

[32] Shi K, Cui F, Yamamoto H, Kawashima Y. Optimized formulation of high payload PLGA nanoparticles containing insulin-lauryl sulphate complex, Drug Dev. Ind. Pharm. 2009; 35: 177-184.

[33] Sun S, Liang N, Piao H, Yamamoto H, Kawashima Y, Cui F. Insulin-S.O (sodium oleate) complex-loaded PLGA nanoparticles: formulation, characterization an in vivo evaluation, J. Microencapsul. 2010; 27: 471-478.

[34] Zhang X, Sun M, Zheng A, Cao D, Bi Y, Sun J. Preparation and characterization of insulin-loaded bioadhesive PLGA. European Journal of Pharmaceutical Sciences 2012; 45: 632-638.

[35] Wu Z, Zhou L, Guo X, Jiang W, Ling L, Qian Y, Luo K, Zhang L. HP55-coated capsule containing PLGA/RS nanoparticles for oral delivery of insulin. International Journal of Pharmaceutics 2012; 425: 1-8.

[36] Sharma G, van der Walle C, Kumar M. Antacid co-encapsulated polyester nanoparticles for peroral delivery of insulin: Development, pharmacokinetics, biodistribution and pharmacodynamics. International Journal of Pharmaceutics doi:10.1016/j.ijpharm.2011.12.038 
[37] Bock N, Dargaville T, Woodruff M. Electrospraying of Polymers with Therapeutic Molecules: State of the Art. Progress in Polymer Science doi:10.1016/j.progpolymsci.2012.03.002.

[38] Cui F, Shi K, Zhang L, Tao A, Kawashima Y. Biodegradable nanoparticles loaded with insulin-phospholipid complex for oral delivery: Preparation, in vitro characterization and in vivo evaluation. Journal of Controlled Release 2006; 114 (2): 242-250.

[39] Damgé C, Maincent P, Ubrich N. Oral delivery of insulin associated to polymeric nanoparticles in diabetic rats. Journal of Controlled Release 2007; 117: 163-170.

[40] Damgé C, Socha M, Ubrich N, Maincent P. Poly( $\varepsilon$-caprolactone)/eudragit nanoparticles for oral delivery of aspart-insulin in the treatment of diabetes. Journal of pharmaceutical sciences 2010; 99 ( 2): 879-889.

[41] Davis S. Drug delivery systems. Interdisciplinary Sci. Rev. 2000; 25: 175-185.

[42] Damge' C, Vranckx H, Balschmidt P, Couvreur P. Poly(alkylcyanoacrylate) nanospheres for oral administration of insulin. J. Pharm. Sci. 1997; 86: 1403-1409.

[43] Graf A, Rades T, Hook S. Oral insulin delivery using nanoparticles based on microemulsions with different structure-types: Optimisation and in vivo evaluation. European journal of pharmaceutical sciences 2009; 3 (7): 53-61.

[44] Pawar H, Douroumis D, Boateng J. Preparation and optimization of PMAA-chitosanPEG nanoparticles for oral drug delivery. Colloids and Surfaces B: Biointerfaces 2012; 90: 102- 108.

[45] Jelvehgari M, Milani P, Siahi-Shadbad M, Loveymi B, Nokhodchi A, Azari Z, Valizadeh H. Development of $\mathrm{pH}$-sensitive insulin nanoparticles using Eudragit L100-55 and chitosan with different molecular weights. AAPS PharmSciTech. 2010; 11 (3): 1237-1242.

[46] Li M, Lu W, Wang J, Zhang X, Wang X, Zheng A, Zhang Q. Distribution, transition, adhesion and release of insulin loaded nanoparticles in the gut of rats. International Journal of Pharmaceutics. 2007; 329: 182-191.

[47] Sarmento B, Ribeiro A, Francisco Veiga F, Ferreira D. Development and characterization of new insulin containing polysaccharide nanoparticles. Colloids and Surfaces B: Biointerfaces. 2006; 53: 193-202.

[48] Russell-Jones G, Westwood S, Farnworth P, Findlay J, Burger H. Synthesis of LHRH antagonists suitable for oral administration via vitamin B12 uptake system, Bioconjug. Chem. 1995; 12: 34-42.

[49] Chalasani K, Russell-Jones, G, Yandrapu, Diwan P, Jain S. A novel vitamin B12nanosphere conjugate carrier system for peroral delivery of insulin. Journal of Controlled Release 2007; 117: 421-429.

[50] Sarmento B, Ferreira D, Veiga F, Ribeiro A. Characterization of insulin-loaded alginate nanoparticles produced by ionotropic pre-gelation through DSC and FTIR studies. Carbohydrate Polymers 2006; 66: 1-7.

[51] Sarmento B, Ribeiro A, Veiga F, Sampaio P, Neufeld R, and Ferreira D. Alginate/Chitosan Nanoparticles are Effective for Oral Insulin Delivery. Pharmaceutical Research, 2007; 24 (12): 724-733.

[52] Zhang N, Li, Jiang W, Ren C, Li J, Xin J, Li K. Effective protection and controlled release of insulin by cationic $\beta$-cyclodextrin polymers from alginate/chitosan nanoparticles. International Journal of Pharmaceutics 2010; 393, 212-218. 
[53] Reis C, Veiga F, Ribeiro A, Neufeld R, Damage C. Nanoparticulate biopolymers deliver insulin orally eliciting pharmacological response. J. Pharm. Sci. 2008; 97 (12) 5290-5305.

[54] Woitiski C, Veiga F, Ribeiro A, Neufeld R. Design for optimization of nanoparticles integrating biomaterials for orally dosed insulin. European Journal of Pharmaceutics and Biopharmaceutics 2009; 73, 25-33.

[55] Woitiskia C, Neufeld R, Veiga F, Carvalhoc R, Figueiredo. Pharmacological effect of orally delivered insulin facilitated by multilayered stable nanoparticles. European Journal of Pharmaceutical Sciences 2010; 41, 556-563.

[56] Sonia T, Sharma C. An overview of natural polymers for oral insulin delivery. Drug Discov Today 2012; http://dx.doi.org/10.1016/j.drudis.2012.03.019.

[57] Muzzarelli R. Chemical and technological advances in chitins and chitosans useful for the Formulation of biopharmaceuticals in Sarmento B, Neves J. (ed.) Chitosan-based systems for biopharmaceuticals: Delivery, Targeting and Polymer Therapeutics. 2012 John Wiley \& Sons, Ltd. 2012; pp. 3-21.

[58] Kittur F, Kumar A, Tharanathan R. Low molecular weight chitosans preparation by depolymerization with Aspergillus niger pectinase, and characterization, Carbohydr. Res. 2003; 338, 1283-1290.

[59] Kumar A, Tharanathan, R. A comparative study on depolymerization of chitosan by proteolytic enzymes, Carbohyd Polym. 2004; 58, 275-283.

[60] Hai L, Bang Diep T, Nagasawa N, Yoshii F, Kume T. Radiation depolymerization of chitosan to prepare oligomers, Nuclear Instruments and Methods in Physics Research B 2003; 208, 466-470.

[61] Cravotto G, Tagliapietra S, Robaldo B, Michele Trotta M. Chemical modification of chitosan under high-intensity ultrasound, Ultrasonics Sonochemistry 2005; 12, 95-98.

[62] Tian F, Liu Y, Hu K, Zhao B. Study of the depolymerization behavior of chitosan by hydrogen peroxide, Carbohydr. Polym. 2004; 57, 31-37.

[63] Mao S, Shuai X, Unger F, Simona M, Bi D, Kissel T. The depolymerization of chitosan: effects on physicochemical and biological properties, Int. J. Pharm. 2004; 281: 45-54.

[64] George M, Abraham T.E. Polyionic hydrocolloids for the intestinal delivery of protein drugs: alginate and chitosan--a review, J. Control Release 2006; 114: 1-14.

[65] Gan Q. Wang T. Chitosan nanoparticle as protein delivery carrier--systematic examination of fabrication conditions for efficient loading and release, Colloids Surf. B Biointerfaces 2007; 59: 24-34.

[66] Chaudhury A, Surajit Das. Recent advancement of chitosan-based nanoparticles for oral controlled delivery of insulin and other therapeutic agents. AAPS PharmSciTech, 2011; 12 (1) $10-20$.

[67] Ma Z, Lim T, Lim, L. Pharmacological activity of peroral chitosan-insulin nanoparticles in diabetic rats, Int. J. Pharm. 2005; 293, 271-280.

[68] Makhlof A, Tozukaa Y, Takeuchi H. Design and evaluation of novel pH-sensitive chitosan nanoparticles for oral insulin delivery. European Journal of Pharmaceutical Sciences 2011; 42, 445-451.

[69] Sonaje K, Lin YH, Juang JH, Wey SP, Chen CT, Sung HW. In vivo evaluation of safety and efficacy of self-assembled nanoparticles for oral insulin delivery. Biomaterials 2009;30(12):2329-2339 
[70] Sonaje K, Chen YJ, Chen HL, Shiaw-Pyng Wey, SP, Juang JH, Nguyen HN, Hsu CW, Lin KJ, Sung HW. Enteric-coated capsules filled with freeze-dried chitosan/poly(gglutamic acid) nanoparticles for oral insulin delivery. Biomaterials 2010; 31, 3384-3394.

[71] Su FY, Lin KJ, Sonaje K, Wey SP, Yen TC, Ho YC, Panda N, Chuang EY, Barnali Maiti B, Sung HW. Protease inhibition and absorption enhancement by functional nanoparticles for effective oral insulin delivery. Biomaterials 2012; 33, 2801-2811.

[72] Mukhopadhyay P, Mishra R, Rana D, Kundu P. Strategies for effective oral insulin delivery with modified chitosan nanoparticles: A review. Progress in Polymer Science. 2012; doi:10.1016/j.progpolymsci.2012.04.004.

[73] Jin Y, Song Y, Zhu X, Zhou D, Chen C, Zhang Z, Huang Y. Goblet cell-targeting nanoparticles for oral insulin delivery and the influence of mucus on insulin transport. Biomaterials 2012; 33, 1573-1582.

[74] Yin L, Ding J, He C, Cui L, Tang C, Yin C. Drug permeability and mucoadhesion properties of thiolated trimethyl chitosan nanoparticles in oral insulin delivery. Biomaterials 2009; 30, 5691-5700.

[75] Sonia T, Sharma C. In vitro evaluation of N-(2-hydroxy) propyl-3-trimethyl ammonium chitosan for oral insulin delivery. Carbohydrate Polymers 2011; 84, 103-109.

[76] Zhu S, Qian F, Zhang Y, Tang C, Yin C. Synthesis and characterization of PEG modified $\mathrm{N}$-trimethylaminoethylmethacrylate chitosan nanoparticles. European Polymer Journal 2007; 43, 2244-2253.

[77] Mao S, Bakowsky U, Jintapattanakit A, Kissel T. Self-assembled polyelectrolyte nanocomplexes between chitosan derivatives and insulin. Int. J. Pharm. 2008; 355, 299-306.

[78] Shelm R, Paul W, Sharma C. Development and characterization of self-aggregated nanoparticles from anacardoylated chitosan as a carrier for insulin. Carbohydrate Polymers 2010; 80, 285-290.

[79] Pouton C, Porter C. Formulation of lipid-based delivery systems for oral administration: Materials, methods and strategies. Adv. Drug Deliv. Rev. 2008; 60, 625-637.

[80] O'Driscoll C, Griffin B. (2008). Biopharmaceutical challenges associated with drugs with low aqueous solubility-The potential impact of lipid-based formulations. Adv. Drug Deliv. Rev. 2008; 60, 617-624.

[81] Morishita M, Matsuzawa A, Takayama K, Isowa K, Nagai T. Improving insulin enteral absorption using water-in-oil-in-water emulsion. Int. J. Pharm. 1998; 172, 189-198.

[82] Shima M, Tanaka M, Fujii T, Egawa K, Kimura Y, Adachi S. Matsuno, R. Oral administration of insulin included in fine $\mathrm{W} / \mathrm{O} / \mathrm{W}$ emulsions to rats. Food Hydrocolloids 2006; 20, 523-531.

[83] Lawrence M, Rees G. Microemulsion-based media as novel drug delivery systems. Adv. Drug Deliv. Rev. 2000; 45, 89-121.

[84] Moulik S, Paul, B. Structure, dynamics and transport properties of microemulsions, Advances in Colloid and Interface Science 1998; 78, 99-195.

[85] Sharma G, Wilson K, van der Walle C, Sattar N, Petrie J, Kumar M. Microemulsions for oral delivery of insulin: Design, development and evaluation in streptozotocin induced diabetic rats. European Journal of Pharmaceutics and Biopharmaceutics 2010; 76 159-169. 
[86] Cilek A, Celebi N, Tirnaksiz F, Tay A. A lecithin-based microemulsion of rh-insulin with aprotinin for oral administration: Investigation of hypoglycemic effects in nondiabetic and STZ-induced diabetic rats. Int. J. Pharm. 2005; 298,176-185.

[87] Kraaling M, Ritschel W. Development of a colonic release capsule dosage form and the absorption of insulin, Methods Find. Exp. Clin. Pharmacol. 1992; 14, 199-209.

[88] Cho Y. Flynn M. Oral delivery of insulin. Lancet 1989; 2, 1518-1519.

[89] Ma E, Ma H, Zheng G, Duan M. In vitro and in vivo evaluation of a novel oral insulin formulation. Acta Pharmacol Sin. 2006; 27 (10) 1382-1388.

[90] Toorisaka E, Hashida M, Kamiya N, Ono H, Kokazu Y, and Goto M. Hypoglycemic effect of surfactant-coated insulin solubilized in a novel solid-in-oil-in-water $(\mathrm{S} / \mathrm{O} / \mathrm{W})$ emulsion. Int.J.Pharm. 2003; 252 (1) 271-274.

[91] Toorisaka E, Hashida M, Kamiya N, Ono H, Kokazu Y, and Goto M. An enteric-coated dry emulsion formulation for oral insulin delivery. J. Control. Release 2005; 107, 91-96.

[92] O'Driscoll, C. Lipid-based formulations for intestinal lymphatic delivery. Eur. J. Pharm Sci.2002; 15, 405-415.

[93] Lin YH, Mi FL, Chen CT, Chang WC, Peng SF, Liang HF, Sung HW. Preparation and characterization of nanoparticles shelled with chitosan for oral insulin delivery. Biomacromolecules 2007; 8, 146-152.

[94] Ma Z, Yeoh HH, Lim LY, Formulation $\mathrm{pH}$ modulates the interaction of insulin with chitosan nanoparticles. J. Pharm. Sci. 2002; 91, 1396-1404.

[95] Sarciaux J, Acar L, and Sado P. Using microemulsion formulations for oral delivery of therapeutic peptides. Int. J. Pharm. 1995; 120, 127-136.

[96] Lyons K, Charman W, Miller R, Porter C. Factors limiting the oral bioavailability of Nacetylglucosaminyl-N-acetylmuramyl dipeptide (GMDP) and enhancement of absorption in rats by delivery in a water-in-oil microemulsion. Int. J. Pharm. 2000; 199, 17-28.

[97] Assaf S, Al-Jbour N, Eftaiha A, Elsayed A, Al Remawi M, Qinna N, Chowdhry B, Leharne $S$ Badwan A. Factors involved in formulation of oily delivery system for proteins based on PEG-8 caprylic/capric glycerides and polyglyceryl-6 dioleate in a mixture of oleic acid with chitosan. Journal of Dispersion Science and Technology 2011;32, 623-633.

[98] Chae S, Jang M, Nah J. Influence of molecular weight on oral absorption of water soluble chitosans, J. Control. Release 2005; 102: 383-394.

[99] Badwan A, Al-Remawi M, Eltaher N, Elsayed A. Nanocapsules for oral delivery of proteins. European Patent (EP2042166) date of publication, 1 April 2009.

[100] Badwan A, Al-Remawi M, Eltaher N, Elsayed A. Oral delivery of protein drug using microemulsion. International patent (WO2007/068311) date of publication, 21 June 2007.

[101] Elsayed A, Al-Remawi M, Qinna N, Farouk A, Badwan A. Formulation and characterization of an oily-based system for oral delivery of insulin. Euro. J. Pharm. Biopharm. 2009; 73: 269-279.

[102] Badwan A, Remawi M, Qinna N, Elsayed A, Arafat T, Melhim M, Abu Hijleh M, Idkaidek N. Enhancement of oral bioavailability of insulin in humans. Neuroendocrinology Letters 2009; 30: 101-105.

[103] Elsayed A, Al-Remawi M, Qinna N, Farouk A, Al-Sou'od K, Badwan A. Chitosansodium Lauryl sulphate nanoparticles as a carrier system for the in Vivo delivery of oral insulin. AAPS Pharm.Sci.Tech. 2011; 12, 958-964. 
[104] Richardson S, Kolbe H, Duncan, R. Potential of low molecular mass chitosan as a DNA delivery system: biocompatibility, body distribution and ability to complex and protect DNA. Int. J. Pharm. 1999; 178, 231-243.

[105] Jeon YJ, Park P, Kim S. Antimicrobial effect of chitooligosaccharides produced by bioreactor. Carbohdr. Polym. 2001; 44, 71-76.

[106] Kondo Y, Nakatani A, Hayashi k, Ito M. (2000). Low molecular weight chitosan prevents the progression of low dose streptozotocin-induced slowly progressive diabetes mellitus in mice. Biol. Pharm. Bull. 2000; 23, 1458-1464.

[107] Qin C, Li H, Xiao Q, Liu Y, Zhu J, Du Y. Water-solubility of chitosan and its antimicrobial activity, Carbohydr. Polym. 2006; 63: 367-374.

[108] Elsayed AM. Oral Insulin Delivery System: Design, Development and Evaluation. PhD thesis. Faculty of Pharmacy, University of Gezira, Wad Medani; 2009.

[109] Morishita M, Matsuzawa A, Takayama K, Isowa K, and Nagai T. Improving insulin enteral absorption using water-in-oil-in-water emulsion. Int. J. Pharm. 1998; 172, 189-198.

[110] Araujo L, Sheppard M, Lobenberg R, Kreuter J. Uptake of PMMA nanoparticles from the gastrointestinal tract after oral administration to rats: modification of the body distribution after suspension in surfactant solutions and in oil vehicles. Int. J. Pharm. $1999 ; 176,209-224$.

[111] Prasad Y, Minamimoto T, Yoshikawa Y, Shibata N, Mori S, Matsuura A, Takada K. In situ intestinal absorption studies on low molecular weight heparin in rats using Labrasol as absorption enhancer, Int. J. Pharm. 2004; 271, 225-232.

[112] Koga K, Kusawake Y, Ito Y, Sugioka N, Shibata N, Takada K. Enhancing mechanism of Labrasol on intestinal membrane permeability of the hydrophilic drug gentamicin sulphate. Eur. J. Pharm. Biopharm. 2006; 64, 82-91.

[113] Clement S, ; Dandona P, Still J, Kosutic G. Oral modified insulin (HIM2) in patients with type 1 diabetes mellitus: results from a phase I/II clinical trial, Metabolism. 2004; 53: 54.

[114] Calceti P, Salmaso S, Walker G, Bernkop-Schnurch A. Development and in vivo evaluation of an oral insulin-PEG delivery system. Eur. J. Pharm. Sci. 2004; 22, 315-323.

[115] Dave N, Hazra P, Khedkar A, Manjunath H, Iyer H, Suryanarayanan S. Process and purification for manufacture of a modified insulin intended for oral delivery. J. Chromatography A 2008; 1177, 282-286.

[116] Malkov D, Angelo R, Wang H, Flanders E, Tang H, and Gomez-Orellana I. (2005). Oral delivery of insulin with the eligen technology: mechanistic studies. Curr Drug Deliv. 2005; 2, 191-197.

[117] Sabetsky V, Ekblom J. Insulin: A new era for an old hormone. Pharmacological Research 2010; 61, 1-4.

[118] Luzio S, Dunseath G, Lockett A, Broke-Smith T, New R, Owens D. The glucose lowering effect of an oral insulin (Capsulin) during an isoglycaemic clamp study in persons with type 2 diabetes. Diabetes, Obesity and Metabolism 2010; 12, 82-87. 